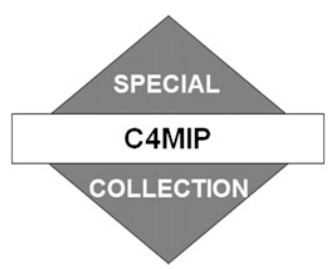

\title{
Long-Term Climate Change Commitment and Reversibility: An EMIC Intercomparison
}

\author{
Kirsten Zickfeld, ${ }^{\mathrm{a}}$ Michael Eby, ${ }^{\mathrm{b}}$ Andrew J. Weaver, ${ }^{\mathrm{b}}$ Kaitlin AleXAnder, ${ }^{\mathrm{b}}$ Elisabeth Crespin, ${ }^{\mathrm{c}}$ \\ NeIl R. Edwards, ${ }^{\mathrm{d}}$ AleXey V. Eliseev, ${ }^{\mathrm{e}}$ GeOrG Feulner, ${ }^{\mathrm{f}}$ ThIERry Fichefet ${ }^{\mathrm{c}}{ }^{\mathrm{C}}$ Chris E. Forest,${ }^{\mathrm{g}}$ \\ Pierre Friedlingstein, ${ }^{\mathrm{h}}$ Hugues Goosse,${ }^{\mathrm{c}}$ Philip B. Holden, ${ }^{\mathrm{d}}$ Fortunat Joos,${ }^{\mathrm{i}}$ Michio Kawamiya, \\ DAVID KICKLIGHTER, ${ }^{\mathrm{k}}$ HeNDRIK KIENERT, ${ }^{\mathrm{f}}$ KATSUMI MATSUMOTO, ${ }^{1}$ IGOR I. MOKHOV, ${ }^{\mathrm{e}}$ ERWAN MONIER, ${ }^{\mathrm{m}}$ \\ Steffen M. Olsen, ${ }^{\mathrm{n}}$ Jens O. P. Pedersen, ${ }^{\circ}$ Mahe Perrette,${ }^{\mathrm{f}}$ Gwenä̈lle PhilipPon-Berthier, ${ }^{\mathrm{c}}$ \\ ANDY RIDGWELl, ${ }^{\mathrm{p}}$ ADAM SCHLOSSER, ${ }^{\mathrm{m}}$ THOMAS SCHNEIDER VON DEIMLING, ${ }^{\mathrm{f}}$ GARY SHAFFER, ${ }^{\mathrm{q}}$ \\ ANDREI SOKOLOV ${ }^{\mathrm{m}}{ }^{\mathrm{R}}$ RENATO SPAHNI, ${ }^{\mathrm{i}}$ MARCO STEINACHER, ${ }^{\mathrm{i}}$ KAORU TACHIIRI ${ }^{\mathrm{j}}$ \\ KATHY S. TOKOs, ${ }^{1}$ MASAKAZU Yoshimori, ${ }^{\mathrm{r}}$ Ning ZENG, ${ }^{\mathrm{s}}$ AND FANG ZHAO \\ ${ }^{a}$ Department of Geography, Simon Fraser University, Burnaby, British Columbia, Canada \\ ${ }^{\mathrm{b}}$ School of Earth and Ocean Sciences, University of Victoria, Victoria, British Columbia, Canada \\ ${ }^{\mathrm{c}}$ Earth and Life Institute, Georges Lemaître Centre for Earth and Climate Research, Université Catholique de Louvain, \\ Louvain-La-Neuve, Belgium \\ ${ }^{\mathrm{d}}$ The Open University, Milton Keynes, United Kingdom \\ ${ }^{\mathrm{e}}$ A. M. Obukhov Institute of Atmospheric Physics, RAS, Moscow, Russia \\ ${ }^{\mathrm{f}}$ Potsdam Institute for Climate Impact Research, Potsdam, Germany \\ ${ }^{\mathrm{g}}$ The Pennsylvania State University, University Park, Pennsylvania \\ ${ }^{\mathrm{h}}$ University of Exeter, Exeter, United Kingdom \\ ${ }^{i}$ Physics Institute, University of Bern, and Oeschger Centre for Climate Change Research, University of Bern, Bern, Switzerland \\ ${ }^{\mathrm{j}}$ Research Institute for Global Change, JAMSTEC, Yokohama, Japan \\ ${ }^{\mathrm{k}}$ The Ecosystems Center, MBL, Woods Hole, Massachusetts \\ ${ }^{1}$ University of Minnesota, Minneapolis, Minnesota \\ ${ }^{\mathrm{m}}$ Massachusetts Institute of Technology, Cambridge, Massachusetts \\ ${ }^{\mathrm{n}}$ Danish Meteorological Institute, Copenhagen, Denmark \\ ${ }^{\circ}$ National Space Institute, Technical University of Denmark, Kongens Lyngby, Denmark \\ ${ }^{\mathrm{P}}$ School of Geographical Sciences, University of Bristol, Bristol, United Kingdom \\ ${ }^{\mathrm{q}}$ Department of Geophysics, University of Concepcion, Concepcion, Chile, and Niels Bohr Institute, University of Copenhagen, \\ Copenhagen, Denmark \\ ${ }^{\mathrm{r}}$ University of Tokyo, Tokyo, Japan \\ ${ }^{\mathrm{s}}$ University of Maryland, College Park, College Park, Maryland
}

(Manuscript received 30 July 2012, in final form 5 February 2013)

\begin{abstract}
This paper summarizes the results of an intercomparison project with Earth System Models of Intermediate Complexity (EMICs) undertaken in support of the Intergovernmental Panel on Climate Change (IPCC) Fifth Assessment Report (AR5). The focus is on long-term climate projections designed to 1) quantify the climate change commitment of different radiative forcing trajectories and 2) explore the extent to which climate change is reversible on human time scales. All commitment simulations follow the four representative concentration pathways (RCPs) and their extensions to year 2300. Most EMICs simulate substantial surface air temperature and thermosteric sea level rise commitment following stabilization of the atmospheric composition at year-2300 levels. The meridional overturning circulation (MOC) is weakened temporarily and recovers to near-preindustrial values in most models for RCPs 2.6-6.0. The MOC weakening is more persistent for RCP8.5. Elimination of anthropogenic $\mathrm{CO}_{2}$ emissions after 2300 results in slowly decreasing atmospheric $\mathrm{CO}_{2}$ concentrations. At year 3000 atmospheric $\mathrm{CO}_{2}$ is still at more than half its year-2300 level in all EMICs for RCPs 4.5-8.5. Surface air temperature remains constant or decreases slightly and thermosteric sea level rise continues for centuries after elimination of $\mathrm{CO}_{2}$ emissions in all EMICs. Restoration of atmospheric $\mathrm{CO}_{2}$ from $\mathrm{RCP}_{\text {to }}$ preindustrial levels over 100-1000 years requires large artificial removal of $\mathrm{CO}_{2}$ from the atmosphere and does not result in the simultaneous return to preindustrial climate conditions, as surface air temperature and sea level response exhibit a substantial time lag relative to atmospheric $\mathrm{CO}_{2}$.
\end{abstract}

Corresponding author address: Kirsten Zickfeld, Department of Geography, Simon Fraser University, 8888 University Drive, Burnaby BC V5A1S6, Canada.

E-mail: kzickfel@sfu.ca

DOI: $10.1175 / J C L I-D-12-00584.1$

(C) 2013 American Meteorological Society 


\section{Introduction}

This paper summarizes the results of a model intercomparison project undertaken in support of the Fifth Assessment Report (AR5) of the Intergovernmental Panel on Climate Change (IPCC). Fifteen groups running Earth System Models of Intermediate Complexity (EMICs) participated in the intercomparison. Coordinated experiments include simulations of the climate of the past millennium and simulations of long-term future climate change, in addition to a set of idealized experiments. This paper discusses the future climate projections (performed by 12 modeling groups), while the idealized and last-millennium simulations are the focus of a separate paper (Eby et al. 2013). The goals of the future climate simulations are 1) to quantify the long-term climate change commitment in response to different radiative forcing trajectories and 2) to explore the extent to which climate change is reversible if atmospheric $\mathrm{CO}_{2}$ is left to evolve freely or is artificially restored to preindustrial levels.

Climate change commitment refers to the climate changes that are to be expected in the future in response to past human activities. The concept of commitment is tied to the thermal inertia of the climate system (Hansen et al. 1985), which causes the effects of greenhouse gas emissions to be felt beyond the duration of those emissions. Climate change commitment is a useful metric for climate science and policy, as it quantifies the minimum climate change humanity faces and represents a benchmark against which to measure the effect of future emissions. Most studies consider the "warming commitment," but here we use the broader term "climate change commitment" to include other aspects of climate change such as sea level rise (Wigley 2005).

Different forms of climate change commitment have been discussed in the literature. The most prominent is the "constant composition" commitment, which refers to the climate changes that are to be expected after stabilization of the chemical composition of the atmosphere, and hence the radiative forcing, at a specified level (Wigley 2005; Meehl et al. 2005; Hare and Meinshausen 2006). This commitment was highlighted in the IPCC Fourth Assessment Report (AR4) and has been estimated at between $0.3^{\circ}$ and $0.9^{\circ} \mathrm{C}$ for the period $2090-99$ relative to $1980-99$ if the atmospheric composition is stabilized at year 2000 levels (Meehl et al. 2007).

Another type of commitment, which has received greater attention more recently, is the "zero emission" commitment, which is the warming that is to be expected after complete elimination of emissions (Hare and Meinshausen 2006; Matthews and Caldeira 2008; Plattner et al. 2008; Eby et al. 2009; Lowe et al. 2009; Frölicher and
Joos 2010; Solomon et al. 2010; Gillett et al. 2011; Zickfeld et al. 2012; Matthews and Zickfeld 2012). Most studies have explored the climate response to elimination of $\mathrm{CO}_{2}$ emissions only. These studies have shown that instantaneous elimination of $\mathrm{CO}_{2}$ emissions results in approximately constant global mean temperature for several centuries after emissions cease. When emissions of non- $\mathrm{CO}_{2}$ greenhouse gases and aerosols also cease (Hare and Meinshausen 2006; Solomon et al. 2010; Frölicher and Joos 2010; Armour and Roe 2011; Matthews and Zickfeld 2012), the climate warms for about a decade and then gradually cools. The initial warming is due to the fast elimination of the negative radiative forcing associated with aerosols, which have a short atmospheric residence time. Greenhouse gases, on the other hand, have a longer atmospheric lifetime and their concentration and associated radiative forcing decline gradually after elimination of emissions. After about a century, the response is largely dominated by the long-lived $\mathrm{CO}_{2}$ and global mean temperature converges to that obtained under elimination of $\mathrm{CO}_{2}$ emissions alone. Matthews and Weaver (2010) argue that the zero emission commitment is a more useful measure of climate change commitment because it does not convolute the physical response of the climate system to past emissions with the response to future emissions that are needed to maintain the atmospheric $\mathrm{CO}_{2}$ concentration at stable levels, as for the constant composition commitment.

Another form of climate change commitment is the "constant emissions" commitment, which refers to the climate changes to be expected in response to constant anthropogenic emissions (Wigley 2005; Hare and Meinshausen 2006). This type of commitment is less prominently discussed in the literature. A study with a simple climate model [the Model for the Assessment of Greenhouse Gas-Induced Climate Change (MAGICC)] estimates the constant emissions commitment at $1.4^{\circ}-$ $2.7^{\circ} \mathrm{C}$ by 2100 (above preindustrial) assuming constant year-2005 emissions (Hare and Meinshausen 2006).

The second set of experiments that is part of this model intercomparison is aimed at exploring the extent to which the climate system can revert to "safe" levels, should climate change impacts turn out to be "dangerous." Insight gained from zero emission commitment simulations suggests that because of the long residence time of $\mathrm{CO}_{2}$ in the atmosphere (Archer and Brovkin 2008; Eby et al. 2009) and the large thermal reservoir of the ocean, complete elimination of emissions can at best lead to stable or slowly decreasing temperatures. If permafrost carbon feedbacks are considered, elimination of emissions could lead to a continuing increase in temperature (MacDougall et al. 2012). Therefore, restoring temperature to lower levels in a time frame meaningful to 
human societies can only be accomplished with "negative emissions" (i.e., net removal of carbon dioxide from the atmosphere). Such negative emissions can be achieved, for instance, by biomass energy in combination with capture and geological storage of the emitted $\mathrm{CO}_{2}$ (BECS; Azar et al. 2006), or by $\mathrm{CO}_{2}$ "scrubbers" that remove the $\mathrm{CO}_{2}$ directly from the atmosphere (Keith et al. 2006).

Few studies to date have explored the response of the climate system to scenarios with negative emissions or "overshoot" scenarios (Yoshida et al. 2005; Tsutsui et al. 2007; Nusbaumer and Matsumoto 2008; Zickfeld et al. 2012). Most of these studies use idealized scenarios, such as atmospheric $\mathrm{CO}_{2}$ increasing gradually to 2 or 4 times the preindustrial level and then decreasing at a similar rate (Held et al. 2010; Boucher et al. 2012). These studies suggest that because of the long time scales of components of the climate system, global mean temperature, precipitation, ocean heat content, and other quantities lag the forcing and revert to the target level only slowly. The residual change (i.e., the difference between the target and the actual level) increases with the level of peak forcing (Held et al. 2010; Boucher et al. 2012). The idealized scenarios used in these papers, which entail large and abrupt decreases in atmospheric $\mathrm{CO}_{2}$, imply levels of negative emissions that are likely beyond known technological capabilities (McGlashan et al. 2012). The set of scenarios used for phase 5 of the Coupled Model Intercomparison Project (CMIP5; Taylor et al. 2012) includes one scenario with moderate negative emissions that is based on plausible technological and economic assumptions [representative concentration pathway (RCP) 2.6; Moss et al. (2010)].

In this paper, we analyze multicentury constant composition, zero emission, and constant emissions commitment simulations with EMICs under a range of radiative forcing scenarios. In addition, we investigate the EMICs' response to a set of reversibility scenarios, whereby atmospheric $\mathrm{CO}_{2}$ is artificially restored to preindustrial levels, or is left to evolve freely after a millennium of constant radiative forcing. Finally, we explore the cumulative $\mathrm{CO}_{2}$ emissions that are compatible with climate stabilization targets using inverse simulations with two EMICs.

The paper is organized as follows. In section 2 we briefly introduce the EMICs that participated in the model intercomparison and describe the experimental setup. In section 3 the results of the model simulations are presented and discussed with reference to the literature. The section starts with a discussion of the ability of EMICs to simulate the climate of the twentieth century, continues with a description of the results of the climate change commitment and reversibility simulations, and ends with a discussion of cumulative emissions compatible with long-term climate targets. Section 4 presents a summary and conclusions.

\section{Methods}

\section{a. Participating models}

This study includes results from 12 EMICs, eight of which are coupled climate-carbon cycle models. The models are the University of Bern 3D Earth system model with Lund-Potsdam-Jena dynamic global vegetation (Bern3D-LPJ; Ritz et al. 2011; Stocker et al. 2011), versions 2.4 and $3 \alpha$ of the Potsdam Institute Climate and Biosphere Model (CLIMBER-2.4, CLIMBER-3 $\alpha$; Petoukhov et al. 2000; Montoya et al. 2005), version 1.0 of the Danish Center for Earth System Science (DCESS) Earth system model (Shaffer et al. 2008), release 2.2.7 of the Grid Enabled Integrated Earth system model (GENIE) adapted with an implementation of land use change (Holden et al. 2013), the A. M. Obukhov Institute of Atmospheric Physics, Russian Academy of Sciences, climate model (IAP RAS CM; Eliseev and Mokhov 2011), version 2.2 of the Massachusetts Institute of Technology's Integrated Global System Model (IGSM2.2; Sokolov et al. 2005), version 1.2 of the Loch-Vecode-Ecbilt-ClioAgism Model (LOVECLIM 1.2; Goosse et al. 2010), version 1.0 of the Minnesota Earth System Model for Ocean biogeochemistry (MESMO 1.0; Matsumoto et al. 2008), the Model for Interdisciplinary Research on Climate (MIROC)-lite-LCM (loosely coupled model; Tachiiri et al. 2010), version 2.0 of the University of Maryland (UMD) Coupled Atmosphere-Biosphere-Ocean model (Zeng et al. 2004), and version 2.9 of the University of Victoria Earth System Climate Model (UVic ESCM 2.9; Weaver et al. 2001; Eby et al. 2009). The characteristics of each model are briefly described in the EMIC intercomparison companion paper (Eby et al. 2013).

A common trait of these models is that they are simplified; that is, they include processes in a more parameterized form and have generally lower resolution compared to atmosphere-ocean general circulation models (AOGCMs) and complex Earth system models (ESMs). The group of EMICs, however, is very heterogeneous, ranging from zonally averaged (Petoukhov et al. 2000) or mixed layer ocean models (Sokolov et al. 2005) coupled to statistical-dynamical models of the atmosphere to low-resolution 3D ocean general circulation models coupled to simplified dynamical models of the atmosphere (Goosse et al. 2010). Eight out of the 12 models include an interactive carbon cycle (Bern3DLPJ, DCESS, GENIE, IGSM2.2, MESMO, MIROClite-LCM, UMD, and UVic). Of these, several models calculate land use emissions internally (Bern3D-LPJ, 
DCESS, GENIE, IGSM 2.2, MIROC-lite-LCM, and UVic) and/or represent seafloor sediment processes, including deep water carbonate sedimentation (Bern3DLPJ, DCESS, GENIE, and UVic).

\section{b. Experimental design}

Most models were spun up with year-850 forcing. The models were then integrated from 850 to 2005 using known natural (orbital, volcanic, and solar) and anthropogenic (greenhouse gas, aerosol, and land cover change) forcing, following phase three of the Paleoclimate Modelling Intercomparison Project (PMIP3)/CMIP5 protocol. Details on the implementation of these forcings in individual EMICs is provided in the appendix of the EMIC intercomparison companion paper (Eby et al. 2013). Note that in this paper we only consider the 1850 2005 portion of the last millennium simulation (henceforth referred to as the "historical" or HIST simulation). The full simulation is discussed in detail in Eby et al. (2013). The MIROC-lite-LCM model was spun up with year-1850 forcing and integrated from 1850 to 2005.

Starting from the end point of the historical simulation, models were integrated with $\mathrm{CO}_{2}$ concentration and non- $\mathrm{CO}_{2}$ greenhouse gas forcing specified according to four RCPs (from 2006 to 2100) and their extensions (to 2300) (Meinshausen et al. 2011). Aerosol forcing (direct effect) and land cover change followed RCP specifications until 2100 and were held constant thereafter. Natural forcings were specified as follows: orbital forcing was held fixed at year-2005 levels, solar irradiance was set to repeat the last solar cycle (19962008 ), and volcanic forcing was set to zero. The atmospheric $\mathrm{CO}_{2}$ concentration of the four RCPs (RCP2.6, $\mathrm{RCP} 4.5, \mathrm{RCP} 6.0$, and $\mathrm{RCP} 8.5$ ) and their extensions is shown in Fig. 1.

From year 2301 to 3000 a set of climate change commitment simulations was performed for all four RCPs. In the constant composition (CCO) commitment simulations, atmospheric $\mathrm{CO}_{2}$ concentration and the forcing from non- $\mathrm{CO}_{2}$ greenhouse gases were held constant at year-2300 levels. Other forcings were held fixed at the level specified for the RCP simulations. A slightly different simulation protocol was followed for the MIROClite-LCM, with constant solar forcing after 2300 (no solar cycle). EMICs with a carbon cycle diagnosed the $\mathrm{CO}_{2}$ emissions compatible with the specified $\mathrm{CO}_{2}$ concentration trajectories.

The commitment runs described in the following were performed with climate-carbon cycle models only. In a second set of simulations, which we designate as the preindustrial $\mathrm{CO}_{2}$ emission (PIEM- $\mathrm{CO}_{2}$ ) commitment experiments, the "anthropogenic $\mathrm{CO}_{2}$ perturbation"defined as the difference in implied $\mathrm{CO}_{2}$ emissions

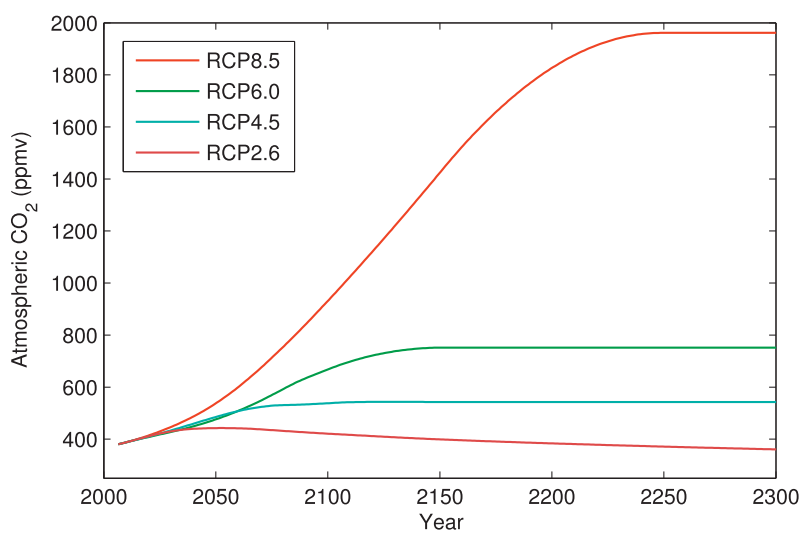

FIG. 1. Time evolution of atmospheric $\mathrm{CO}_{2}$ between 2006 and 2300 for the four RCPs and their extensions (RCP database version 2.0; http://tntcat.iiasa.ac.at:8787/RcpDb/).

between the last decade of the RCP simulations (2290-2300) and the decade 1840-50 of the historical simulation-was set to zero starting in 2300 , while the radiative forcing from non- $\mathrm{CO}_{2}$ greenhouse gases was held fixed at year-2300 levels. Other forcings were held fixed at the level specified for the RCP simulations. For the GENIE model, $\mathrm{CO}_{2}$ emissions were set to zero after 2300. It should be noted that in most models, setting the anthropogenic perturbation to zero did not result in zero emissions exactly. The reason is that the 1840-50 land-atmosphere and ocean-atmosphere $\mathrm{CO}_{2}$ fluxes in response to forcing are not exactly consistent with the specified atmospheric $\mathrm{CO}_{2}$. Diagnosed emissions are negative in all models (except UMD), implying a flux of $\mathrm{CO}_{2}$ from the land and ocean to the atmosphere. Processes responsible for the excess emissions could be the warming recovery after volcanic eruption, or land use change.

In the preindustrial emission (PIEM) simulations, $\mathrm{CO}_{2}$ emissions after 2300 were specified as in the PIEM- $\mathrm{CO}_{2}$ simulation, but the radiative forcing from non- $\mathrm{CO}_{2}$ greenhouse gases was set to $1840-50$ average levels. Other forcings were held fixed at the level specified for the RCP simulations.

In the constant emission (CEM) commitment simulations, implied $\mathrm{CO}_{2}$ emissions over the last decade of the RCP integrations (years 2290-2300) were diagnosed, and held fixed at this value from year 2300 onward. Radiative forcing from non- $\mathrm{CO}_{2}$ greenhouse gases was held constant at year-2300 levels and other forcings were held fixed at the level specified for the RCP simulations.

In addition to the commitment simulations, a set of reversibility runs (RE) was also performed by several EMIC groups. These simulations start from the year3000 model configuration of the $\mathrm{CCO}$ experiments and extend to the year 4000. In the first experiment (REa), 
TABLE 1. Model experiments.

\begin{tabular}{|c|c|c|c|c|c|}
\hline Expt & Simulation & Timeframe & $\mathrm{CO}_{2}$ forcing & $\begin{array}{l}\text { Non- } \mathrm{CO}_{2} \text { greenhouse } \\
\text { gas forcing }\end{array}$ & $\begin{array}{l}\text { No. of } \\
\text { models }\end{array}$ \\
\hline HIST & Historical & $1850-2005$ & CMIP5 concentration & CMIP5 forcing & 12 \\
\hline $\mathrm{RCP}$ & $\begin{array}{l}\text { Representative concentration } \\
\text { pathways and extensions }\end{array}$ & $2006-2300$ & CMIP5 concentration & CMIP5 forcing & 12 \\
\hline $\mathrm{CCO}$ & $\begin{array}{l}\text { Constant composition } \\
\text { commitment }\end{array}$ & $2301-3000$ & Constant year- 2300 concentration & Constant year-2300 forcing & 12 \\
\hline PIEM-CO ${ }_{2}$ & $\begin{array}{l}\text { Preindustrial } \mathrm{CO}_{2} \text { emission } \\
\text { commitment }\end{array}$ & $2301-3000$ & Constant $1840-50$ emissions & Constant year-2300 forcing & 7 \\
\hline PIEM & $\begin{array}{l}\text { Preindustrial emission } \\
\text { commitment }\end{array}$ & $2301-3000$ & Constant $1840-50$ emissions & Constant $1840-50$ forcing & 7 \\
\hline CEM & Constant emission commitment & $2301-3000$ & Constant 2290-2300 emissions & Constant year-2300 forcing & 7 \\
\hline $\mathrm{REa}$ & Reversibility a & $3001-4000$ & $\begin{array}{l}\text { Linear decrease in concentration } \\
\text { over } 100 \mathrm{yr}\end{array}$ & Constant year-2300 forcing & 11 \\
\hline $\mathrm{REb}$ & Reversibility b & $3001-4000$ & $\begin{array}{l}\text { Linear decrease in concentration } \\
\text { over } 1000 \mathrm{yr}\end{array}$ & Constant year-2300 forcing & 11 \\
\hline REc & Reversibility c & $3001-4000$ & Zero emissions & Constant year-2300 forcing & 7 \\
\hline TTR & Temperature tracking & $2005-2500$ & Diagnosed & $\begin{array}{l}\text { Linear decrease to zero } \\
\text { by } 2300\end{array}$ & 2 \\
\hline
\end{tabular}

atmospheric $\mathrm{CO}_{2}$ decreases linearly to the preindustrial level over $100 \mathrm{yr}$, while non- $\mathrm{CO}_{2}$ forcings are held fixed at year-3000 levels. Forcing specifications are similar in the second experiment $(\mathrm{REb})$, except that $\mathrm{CO}_{2}$ is prescribed to decrease to preindustrial levels over a period of $1000 \mathrm{yr}$. In the third experiment (REc), atmospheric $\mathrm{CO}_{2}$ is allowed to evolve freely (zero $\mathrm{CO}_{2}$ emissions) and non- $\mathrm{CO}_{2}$ forcings are again held fixed at year-3000 levels. The REc experiments with freely evolving atmospheric $\mathrm{CO}_{2}$ were performed by EMICs with an interactive carbon cycle only.

Finally, a set of simulations was carried out whereby a temperature stabilization trajectory was specified, and the cumulative emissions consistent with that temperature trajectory were calculated, following the inverse modeling approach described in Zickfeld et al. (2009). Four temperature tracking (TTR) simulations were performed, with global mean surface air temperatures stabilizing at $1.5^{\circ}, 2^{\circ}, 3^{\circ}$, and $4^{\circ} \mathrm{C}$ warming relative to preindustrial. The simulations started from the end of the historical simulation and were integrated to year 2500 . Natural forcings were specified as in the RCP simulations. Land use change was held constant at the year-2005 pattern, whereas non- $\mathrm{CO}_{2}$ greenhouse gas and aerosol forcing linearly decreased from year-2005 values to zero by 2300. All model simulations are summarized in Table 1.

\section{Results and discussion}

\section{a. Historical simulation}

The performance of EMICs over the historical period is discussed in detail in Eby et al. (2013). Here, we briefly summarize the main findings to allow the reader to put the EMICs' future projections and their uncertainty ranges into perspective.
Over the twentieth century EMICs simulate a model ensemble mean warming of $0.78^{\circ} \mathrm{C}$ (range: $0.4^{\circ}-1.2^{\circ} \mathrm{C}$ ), compared to the observed warming of $0.73^{\circ} \mathrm{C}$ (Morice et al. 2013) over the same period (Table 2). Five models stay mostly within the observational uncertainty envelope for this period, five tend to overestimate the observed warming, and two tend to underestimate it (see Fig. 1b of Eby et al. 2013). The spread in the models is a result of different climate sensitivities and differences in the specification of radiative forcing, particularly from land use change and tropospheric aerosols (Eby et al. 2013).

EMICs simulate a model-mean rate of ocean thermal expansion for 1955-2010 of $0.9 \mathrm{~mm} \mathrm{yr}^{-1}$ compared to the observations-based estimate of $0.54 \mathrm{~mm} \mathrm{yr}^{-1}$ for the upper 0-2000 m of the world ocean (Levitus et al. 2012). Most EMICs overestimate the observed rate of thermal expansion. The observed trend is for the upper 0-2000 m of the ocean only, whereas the modeled estimates are for the entire ocean, but the contribution of the deep ocean to the thermal expansion trend $\left[0.11 \mathrm{~mm} \mathrm{yr}^{-1}\right.$ for 1992 2005; Purkey and Johnson (2010)] is unlikely to explain the entire difference. Ocean thermal expansion is determined by both the models' heat uptake efficacy and climate sensitivity, which differ largely between models (see Table 2 of Eby et al. 2013).

The atmospheric $\mathrm{CO}_{2}$ concentration was specified in the historical simulation and EMICs with an interactive carbon cycle were used to diagnose the $\mathrm{CO}_{2}$ emissions compatible with the specified $\mathrm{CO}_{2}$ concentrations. The average EMIC carbon cycle response for the 1990s is within the uncertainty range of observed values (Denman et al. 2007), except for diagnosed emissions, which are slightly underestimated (Table 2). Ocean fluxes simulated 
TABLE 2. Changes in climate and carbon cycle variables from EMIC historical simulations and observations. Shown are the warming over the twentieth century $(\Delta T)$, the rate of thermosteric sea level rise averaged over 1971-2010 $\left(\mathrm{SLR}_{\mathrm{th}}\right)$, the carbon fluxes averaged over 1990-99, and cumulative fluxes from 1800 to 1994 . Here Land $_{\text {LUC }}$ are land-use change fluxes from simulations with land-use forcing only (see Eby et al. 2013); Land $\mathrm{RES}_{\text {is }}$ the residual land flux, which is derived as the difference between the land flux from the historical simulation with all forcings and $\mathrm{Land}_{\mathrm{LUC}}$. Carbon fluxes are positive when directed into the atmosphere. Observation-based estimates are from Morice et al. (2013) for the twentieth-century warming, Levitus et al. (2012) for 1955-2010 thermal expansion for the 0-2000-m layer of the World Ocean, Denman et al. (2007, their Table 7.1) for the 1990s carbon fluxes, and Sabine et al. (2004) for the cumulative carbon fluxes.

\begin{tabular}{|c|c|c|c|c|c|c|c|c|c|}
\hline \multirow[b]{2}{*}{ Model } & \multirow[b]{2}{*}{$\Delta T\left({ }^{\circ} \mathrm{C}\right)$} & \multirow{2}{*}{$\underset{\left(\mathrm{mm} \mathrm{yr}^{-1}\right)}{\mathrm{SLR}_{\mathrm{th}}}$} & \multicolumn{4}{|c|}{ 1990s carbon fluxes $\left(\mathrm{PgC} \mathrm{yr}^{-1}\right)$} & \multicolumn{3}{|c|}{ Cumulative fluxes $1800-1994(\mathrm{PgC})$} \\
\hline & & & $\operatorname{Land}_{\text {LUC }}$ & Land $_{\text {RES }}$ & Ocean & Emissions & Land & Ocean & Emissions \\
\hline Bern3D-LPJ & 0.57 & 0.60 & 0.7 & -0.8 & -1.8 & 5.2 & 108 & -104 & 167 \\
\hline CLIMBER-2 & 0.91 & 1.38 & - & - & - & - & - & - & - \\
\hline CLIMBER-3 & 0.91 & 1.29 & - & - & - & - & - & - & - \\
\hline DCESS & 0.84 & 0.89 & 0.3 & -0.9 & -1.8 & 5.7 & 4 & -102 & 260 \\
\hline GENIE & 1.00 & 0.85 & 0.5 & -1.4 & -2.1 & 6.1 & 21 & -114 & 251 \\
\hline IAP RAS CM & 0.80 & - & - & - & - & - & - & - & - \\
\hline IGSM & 0.70 & 0.43 & 0.3 & -0.7 & -2.2 & 5.9 & 43 & -122 & 237 \\
\hline LOVECLIM & 0.38 & 0.51 & - & - & - & - & - & - & - \\
\hline MESMO & 1.15 & 0.95 & & -0.6 & -1.9 & 5.9 & -28 & -102 & 305 \\
\hline MIROC-lite-LCM & 0.70 & 0.69 & & $-0.1^{\mathrm{a}}$ & -1.6 & 5.4 & $108^{\mathrm{b}}$ & $-86^{\mathrm{b}}$ & $140^{\mathrm{b}}$ \\
\hline UMD & 0.79 & 1.33 & & -0.6 & -2.4 & 6.2 & -51 & -136 & 344 \\
\hline UVic & 0.75 & 1.18 & 1.3 & -1.2 & -2.0 & 5.2 & 24 & -112 & 244 \\
\hline EMIC mean ${ }^{c}$ & $0.78^{\mathrm{d}}$ & 0.92 & 0.6 & -1.0 & $-1.9^{\mathrm{d}}$ & 5.6 & 40 & -111 & 233 \\
\hline EMIC range $^{c}$ & 0.38 to 1.15 & 0.43 to 1.38 & 0.3 to 1.3 & -1.4 to -0.7 & -2.2 to -1.6 & 5.2 to 6.1 & 4 to 108 & -122 to -102 & 156 to 258 \\
\hline Observed & 0.73 & 0.54 & 1.6 & -2.6 & -2.2 & 6.4 & 39 & -118 & 244 \\
\hline Uncertainty & & 0.49 to 0.59 & 0.5 to 2.7 & -4.3 to -0.9 & -2.6 to -1.8 & 6.0 to 6.8 & 11 to 67 & -137 to -99 & 224 to 264 \\
\hline
\end{tabular}

${ }^{a}$ Land use change fluxes could not be diagnosed for this model because of the lack of a historical simulation with land use change forcing only.

${ }^{\mathrm{b}}$ Cumulative fluxes for this model are for 1851-1994.

${ }^{c}$ The MESMO and UMD models were excluded from the EMIC mean and range for the carbon cycle variables because they did not simulate land use change fluxes. Only the total land flux is reported for these models. The MIROC-lite-LCM model was excluded from the EMIC mean and range for the 1800-1994 cumulative fluxes because no carbon flux data were available prior to 1851 .

${ }^{\mathrm{d}}$ These values differ slightly from those reported in Eby et al. (2013) because of a different subset of EMICs included in the calculation.

by all but one EMIC are within the uncertainty range of observed values. Although the EMIC average land fluxes fall within the large range of uncertainty, several models underestimate both the land use change flux and the residual land flux (i.e., the total land-atmosphere flux minus the land use change flux).

The EMICs' cumulative carbon fluxes from 1800 to 1994 are compared to estimates from Sabine et al. (2004). Again, all models estimate total ocean uptake within the uncertainty range of observed values (Table 2). Land uptake differs substantially between models, with only half of the models' simulated fluxes falling within the estimated uncertainty range. EMICs whose land flux agrees well with observation also simulate 1800-1994 cumulative emissions within the observed range. Overall, the twentieth-century climate and carbon cycle response simulated by EMICs agrees reasonably well with observations, which supports the use of EMICs to project longterm climate change and to complement more complex AOGCMs and ESMs.

\section{b. Constant composition commitment}

Figure 2 shows the time evolution of physical climate variables for the constant composition commitment simulations. At the multicentury time scale considered in this study, the warming depends strongly on the forcing scenario, being highest in RCP8.5 and lowest in the low-emission RCP2.6 scenario. Following the radiative forcing the model ensemble mean temperature under the RCP2.6 scenario peaks at year 2070 and declines until reaching a minimum in 2300 , after which it slowly increases again. Global mean temperature under $\mathrm{RCP} 2.6$ peaks at $1.0^{\circ} \mathrm{C}$ relative to $1986-2005$ in the ensemble mean (model range: $0.6^{\circ}-1.4^{\circ} \mathrm{C}$ ) and decreases to $0.6^{\circ} \mathrm{C}\left(0.2^{\circ}-1.1^{\circ} \mathrm{C}\right)$ at 2300 . Assuming an observed warming of $0.7^{\circ} \mathrm{C}$ between 1850 and 2005 , the ensemble mean peak and year-2300 warming are $1.7^{\circ}$ and $1.3^{\circ} \mathrm{C}$ above preindustrial, respectively. In a few models, however, peak warming exceeds $2.0^{\circ} \mathrm{C}$ relative to preindustrial (Fig. 3). 

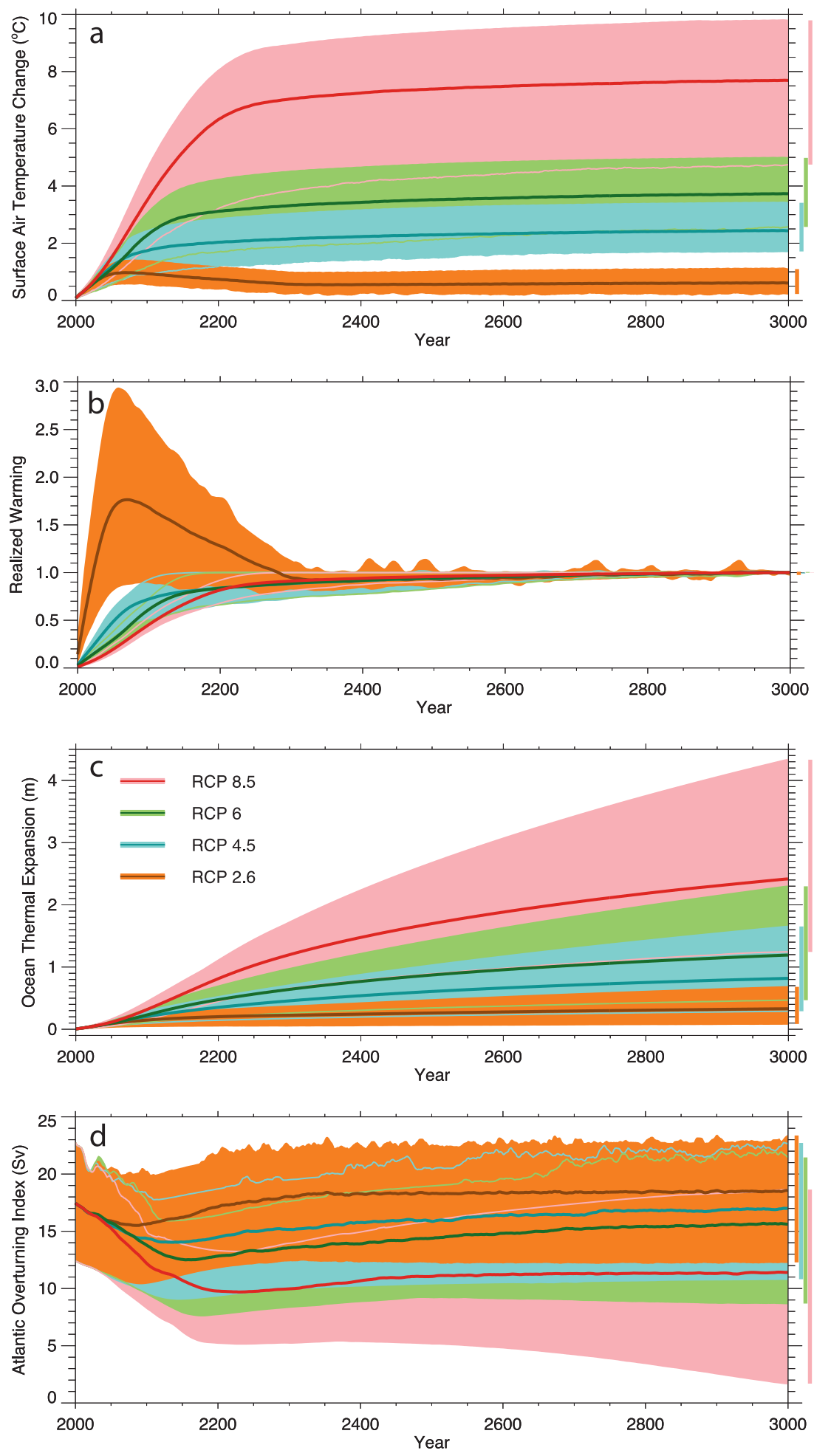

FIG. 2. Time evolution of physical climate variables for the CCO commitment simulations under the four RCP scenarios: (a) surface air temperature change, (b) the fraction of realized warming (calculated as the ratio of warming at any time to the warming averaged over 29813000), (c) ocean thermal expansion, and (d) the Atlantic overturning index, defined as the maximum value of the overturning streamfunction in the North Atlantic. Anomalies are relative to 1986-2005. Shown are the model ensemble averages (thick solid lines), the ranges spanned by all models (shaded domains, delimited by thin solid lines), and the range in the year 3000 (vertical bars on right side). Data were smoothed using a 10-yr moving average. 

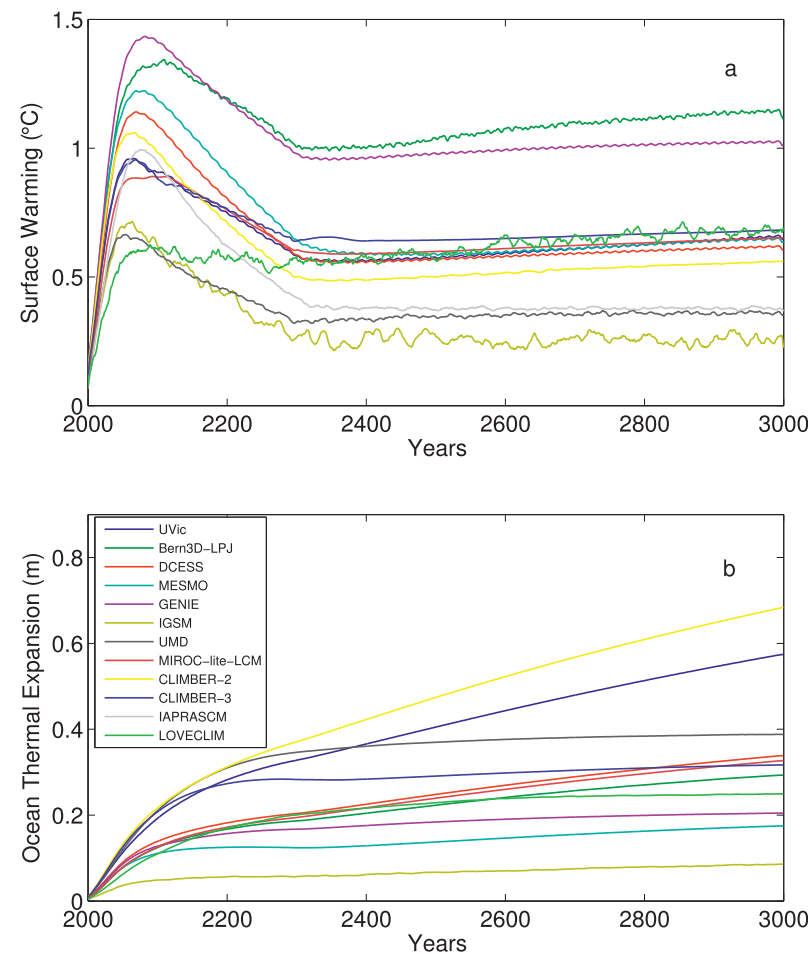

FIG. 3. RCP2.6 CCO commitment simulations: (a) surface air temperature change and (b) ocean thermal expansion. Anomalies are relative to 1986-2005. Data in (a) were smoothed using a 10-yr moving average.

Under the other RCP scenarios (RCP4.5, RCP6.0, and $\mathrm{RCP} 8.5$ ) the global temperature increases rapidly until the time of stabilization of the forcing, and more slowly thereafter. By 2300, global warming approaches $2.2^{\circ} \mathrm{C}$ under $\mathrm{RCP} 4.5,3.3^{\circ} \mathrm{C}$ under $\mathrm{RCP} 6.0$, and $7.0^{\circ} \mathrm{C}$ under RCP8.5 in the ensemble mean (relative to 19862005). The ensemble means and model ranges are generally consistent with those simulated by AOGCMs and ESMs contributing to the CMIP5 (Table 3).

Most EMICs simulate a considerable warming commitment following stabilization of radiative forcing at year-2300 levels. The continuing albeit slower warming after stabilization is a well-known feature of climate models and is associated with the large thermal inertia of the ocean (Hansen et al. 1985). IPCC AR4 models estimated the additional warming after stabilization of the atmospheric composition at year-2000 levels at $0.6^{\circ} \mathrm{C}$ for the period 2090-99 relative to 1980-99 (Meehl et al. 2007), or $0.3^{\circ} \mathrm{C}$ relative to 2000 . A year-2000 constant composition commitment simulation is not part of this EMIC intercomparison, so direct comparison with IPCC AR4 results are not possible. However, the EMIC mean warming of $0.5^{\circ} \mathrm{C}$ between 2100 (the time of stabilization of the forcing) and 2300 for the RCP4.5 constant composition simulation is consistent with the IPCC AR4 estimate. The additional warming between 2300 and 3000 is $0.3^{\circ}, 0.5^{\circ}$, and $0.8^{\circ} \mathrm{C}$ in the ensemble mean for RCPs 4.5 , 6.0 , and 8.5 , respectively, indicating a slight increase with radiative forcing. Another measure of constant composition commitment is the fraction of realized warming (Solomon et al. 2009), which is here estimated as the ratio of warming at a given time to the warming averaged over the last two decades of the simulation (2981-3000) (Fig. 2). At the time of stabilization of radiative forcing, the fraction of realized warming is about $70 \%-90 \%$ in the ensemble mean for RCPs 4.5, 6.0, and 8.5.

Sea level rise due to thermal expansion (thermosteric sea level rise) continues for centuries after stabilization of radiative forcing in all scenarios because of the long response time scale of the deep ocean. Despite the peaking and declining radiative forcing under RCP2.6, the rate of thermosteric sea level rise is positive throughout the duration of the simulation in all models (Fig. 3). Thermal expansion simulated by EMICs for the four RCPs and selected time periods is given in Table 3. The model mean thermal expansion by 2100 agrees very well with that simulated by CMIP5 models (Yin 2012).

The thermosteric sea level rise commitment after stabilization of radiative forcing is substantial under RCPs $4.5,6.0$, and 8.5 and at year 3000 amounts to $1.5-3$ times the thermosteric sea level rise at the time of forcing stabilization. Note that none of the EMICs include sea level rise resulting from melting of land-based glaciers and ice sheets. Consideration of these contributions would lead to substantially higher sea level rise estimates, but the exact value is highly uncertain because of incomplete understanding of glacier and ice sheet dynamics.

The Atlantic meridional overturning circulation (MOC) weakens under all scenarios (Fig. 2). Under RCPs 2.6, 4.5, and 6.0 the weakening is temporary, and the circulation recovers to within $80 \%$ of the preindustrial strength at the end of the simulation in most models. Under RCP8.5 the weakening is more persistent, and the model ensemblemean MOC recovers to $60 \%$ of the preindustrial strength at 3000 . Under this scenario the MOC response varies considerably among models; while in some models the circulation recovers to near preindustrial values, it is close to a complete collapse in the Bern3D-LPJ EMIC.

Comparison of constant composition commitment estimates with those from an earlier EMIC intercomparison (Plattner et al. 2008) is hampered by the use of different scenarios [Special Report on Emissions Scenarios (SRES) as opposed to RCPs] and sets of models used. However, given the similarity of the SRES B1 stabilization scenario and RCP4.5 (in both scenarios atmospheric $\mathrm{CO}_{2}$ stabilizes at $550 \mathrm{ppmv}$ ), we attempted a comparison of the warming and thermal expansion commitment for 
TABLE 3. Global mean warming and thermal expansion relative to the 1986-2005 reference period for selected time periods and four RCPs. CMIP5 surface air temperature anomalies (Knutti and Sedláček 2013) and thermal expansion (Yin 2012) are shown for comparison. Listed are the model ensemble mean and the minimum and maximum values from the model distribution in parentheses. CMIP5 thermal expansion values are relative to 2006. EMIC year 2981-3000 values are from the CCO simulations.

\begin{tabular}{|c|c|c|c|c|c|}
\hline \multirow[b]{2}{*}{ Scenario } & \multicolumn{2}{|c|}{$2081-2100$} & \multicolumn{2}{|c|}{$2281-2300$} & \multirow{2}{*}{$\begin{array}{c}\text { 2981-3000 } \\
\text { EMIC }\end{array}$} \\
\hline & EMIC & CMIP5 & EMIC & CMIP5 & \\
\hline & & & Warming $\left({ }^{\circ} \mathrm{C}\right)$ & & \\
\hline RCP2.6 & $1.0(0.6,1.4)$ & $1.0(0.0,2.0)$ & $0.6(0.3,1.0)$ & - & $0.6(0.3,1.1)$ \\
\hline $\mathrm{RCP} 4.5$ & $1.7(0.9,2.4)$ & $1.8(1.0,2.8)$ & $2.2(1.3,3.0)$ & - & $2.5(1.7,3.5)$ \\
\hline RCP6.0 & $2.1(1.1,2.8)$ & $2.3(1.5,3.2)$ & $3.3(1.9,4.5)$ & - & $3.8(2.6,5.0)$ \\
\hline \multirow[t]{2}{*}{ RCP8.5 } & $3.1(1.6,4.1)$ & $3.7(2.5,5.0)$ & $7.0(3.8,8.9)$ & - & $7.8(4.7,9.8)$ \\
\hline & & & Thermal expansion (m) & & \\
\hline RCP2.6 & $0.14(0.05,0.20)$ & $0.13(0.10,0.18)$ & $0.22(0.06,0.37)$ & $0.21(0.14,0.27)$ & $0.33(0.09,0.68)$ \\
\hline $\mathrm{RCP} 4.5$ & $0.18(0.09,0.26)$ & $0.18(0.14,0.22)$ & $0.45(0.17,0.69)$ & $0.52(0.37,0.63)$ & $0.82(0.29,1.64)$ \\
\hline RCP6.0 & $0.20(0.10,0.29)$ & - & $0.62(0.26,0.95)$ & - & $1.20(0.47,2.29)$ \\
\hline RCP8.5 & $0.27(0.13,0.38)$ & $0.28(0.22,0.37)$ & $1.17(0.64,1.66)$ & $1.19(0.95,1.45)$ & $2.48(1.24,4.31)$ \\
\hline
\end{tabular}

these two scenarios. The additional warming between years 2100 and 3000 is larger in Plattner et al. (2008) than in this study $\left(0.6^{\circ}-1.6^{\circ} \mathrm{C}\right.$ for SRES B1 versus $0.1^{\circ}-$ $1.2^{\circ} \mathrm{C}$ for RCP4.5), but with a similar intermodel range $\left(\sim 1.0^{\circ} \mathrm{C}\right)$. Thermal expansion commitment is similar in the two studies, with the range simulated in this study encompassing the range of Plattner et al. (2008) (0.3-1.1 m for SRES B1 versus 0.2-1.4 m for RCP4.5). Differences in warming and thermal expansion commitment may be as a result of the different sets of models used in the two intercomparisons, but also to differences in non- $\mathrm{CO}_{2}$ forcing between scenarios.

EMICs with an interactive carbon cycle were used to diagnose the $\mathrm{CO}_{2}$ emissions compatible with the $\mathrm{CO}_{2}$ concentration pathways specified under the constant composition commitment simulations. Diagnosed $\mathrm{CO}_{2}$ emissions are estimated by closing the global-mean carbon budget of the atmosphere and are determined by the atmosphere-land and atmosphere-ocean $\mathrm{CO}_{2}$ fluxes. Figure 4 shows $\mathrm{CO}_{2}$ emissions and changes in carbon inventories since 1850 simulated by eight EMICs for scenario RCP2.6. $\mathrm{CO}_{2}$ emissions peak around 2020 and decline steeply thereafter. Since the rate of atmospheric $\mathrm{CO}_{2}$ decrease exceeds the rate of $\mathrm{CO}_{2}$ uptake by carbon sinks, diagnosed emissions become negative in all models. Minimum emissions range from -1.5 to $-0.5 \mathrm{PgC} \mathrm{yr}^{-1}$. After stabilization of atmospheric $\mathrm{CO}_{2}$, emissions settle at a slightly positive value (equal to the rate of $\mathrm{CO}_{2}$ uptake by carbon sinks). Cumulative $\mathrm{CO}_{2}$ emissions since 1850 vary substantially among models despite identical prescribed atmospheric $\mathrm{CO}_{2}$ and range from 300 to $830 \mathrm{PgC}$ at 2300 and from 380 to $1040 \mathrm{PgC}$ at year 3000. The airborne fraction of cumulative emissions decreases from $45 \%-70 \%$ at the time of peak atmospheric $\mathrm{CO}_{2}$ (year 2050) to $15 \%-42 \%$ at the end of the simulation.
Accumulated land carbon uptake is negative at the year 2000 in all models that simulate land use change (LUC) emissions interactively on the basis of land cover changes (all EMICs except MESMO and UMD). The reason is that $\mathrm{CO}_{2}$ emissions resulting from land use exceed net $\mathrm{CO}_{2}$ uptake by vegetation during most of the historical period (Eby et al. 2013). Between 2000 and the year of peak atmospheric $\mathrm{CO}_{2}$, the terrestrial biosphere acts as a sink of $\mathrm{CO}_{2}$ in most models (except in Bern3DLPJ and UVic). Between the $\mathrm{CO}_{2}$ peak and the time of $\mathrm{CO}_{2}$ stabilization, the terrestrial biosphere becomes a source of $\mathrm{CO}_{2}$ in all models. The range in land carbon uptake under the RCP2.6 scenario is spanned by the UMD model at the upper end, which has a small land uptake sensitivity to $\mathrm{CO}_{2}\left(\beta_{L}\right)$ but also a small sensitivity to temperature $\left(\gamma_{L}\right)$ (Eby et al. 2013) and does not simulate LUC emissions, and the Bern3D-LPJ and UVic models at the lower end (both models have large land uptake sensitivities to $\mathrm{CO}_{2}$ but also medium to large sensitivities to temperature and do simulate LUC emissions). The fraction of cumulative emissions taken up by the land (land uptake fraction) decreases between 2100 and 2300 and remains approximately constant thereafter.

The ocean takes up carbon from the atmosphere throughout the duration of the RCP 2.6 constant composition simulation in all models. Ocean carbon uptake slows after the peak in atmospheric $\mathrm{CO}_{2}$ and accelerates again after $\mathrm{CO}_{2}$ is stabilized. Accumulated ocean carbon uptake is larger than accumulated land carbon uptake at all times in all models. The range in ocean carbon uptake is spanned by the UMD model at the upper end [highest ocean carbon uptake sensitivity to $\mathrm{CO}_{2}\left(\gamma_{O}\right)$; Eby et al. 2013] and the UVic model (low carbon uptake sensitivity to $\mathrm{CO}_{2}$ ). The ocean uptake fraction increases continuously between the time of peak $\mathrm{CO}_{2}$ and 2300, and remains approximately constant thereafter. 

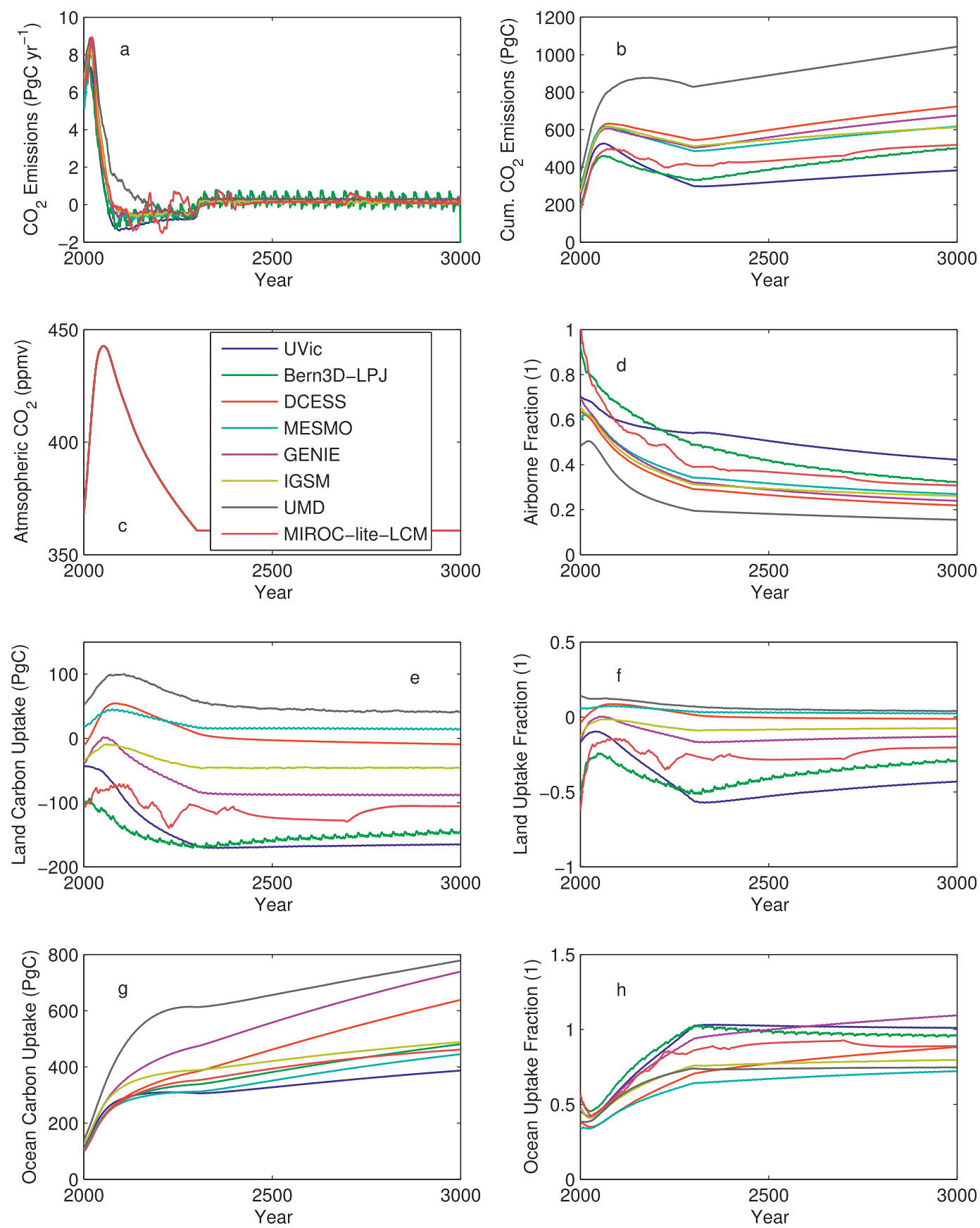

FIG. 4. Changes in carbon inventories in RCP2.6 CCO commitment simulations for eight EMICs with an interactive carbon cycle: (a) $\mathrm{CO}_{2}$ emissions, (b) cumulative $\mathrm{CO}_{2}$ emissions since 1850 , (c) atmospheric $\mathrm{CO}_{2}$ concentration, (d) airborne fraction of cumulative emissions, (e) land uptake since 1850, (f) fraction of cumulative emissions taken up by land, (g) ocean uptake since 1850 , and (h) fraction of cumulative emissions taken up by ocean. Note that for individual models the ocean uptake fraction can be $>1$, if the land uptake fraction is $<0$. Data in (a) were smoothed using a 10-yr moving average.

Figure 5 displays changes in carbon inventories in the year 3000 for constant composition commitment simulations under all four RCPs. Diagnosed cumulative $\mathrm{CO}_{2}$ emissions increase approximately linearly with atmospheric $\mathrm{CO}_{2}$ for RCPs 2.6-6.0, but the increase becomes less than linear at higher radiative forcing in most models. The spread in cumulative emissions diagnosed by models also increases with higher atmospheric $\mathrm{CO}_{2}$, with 

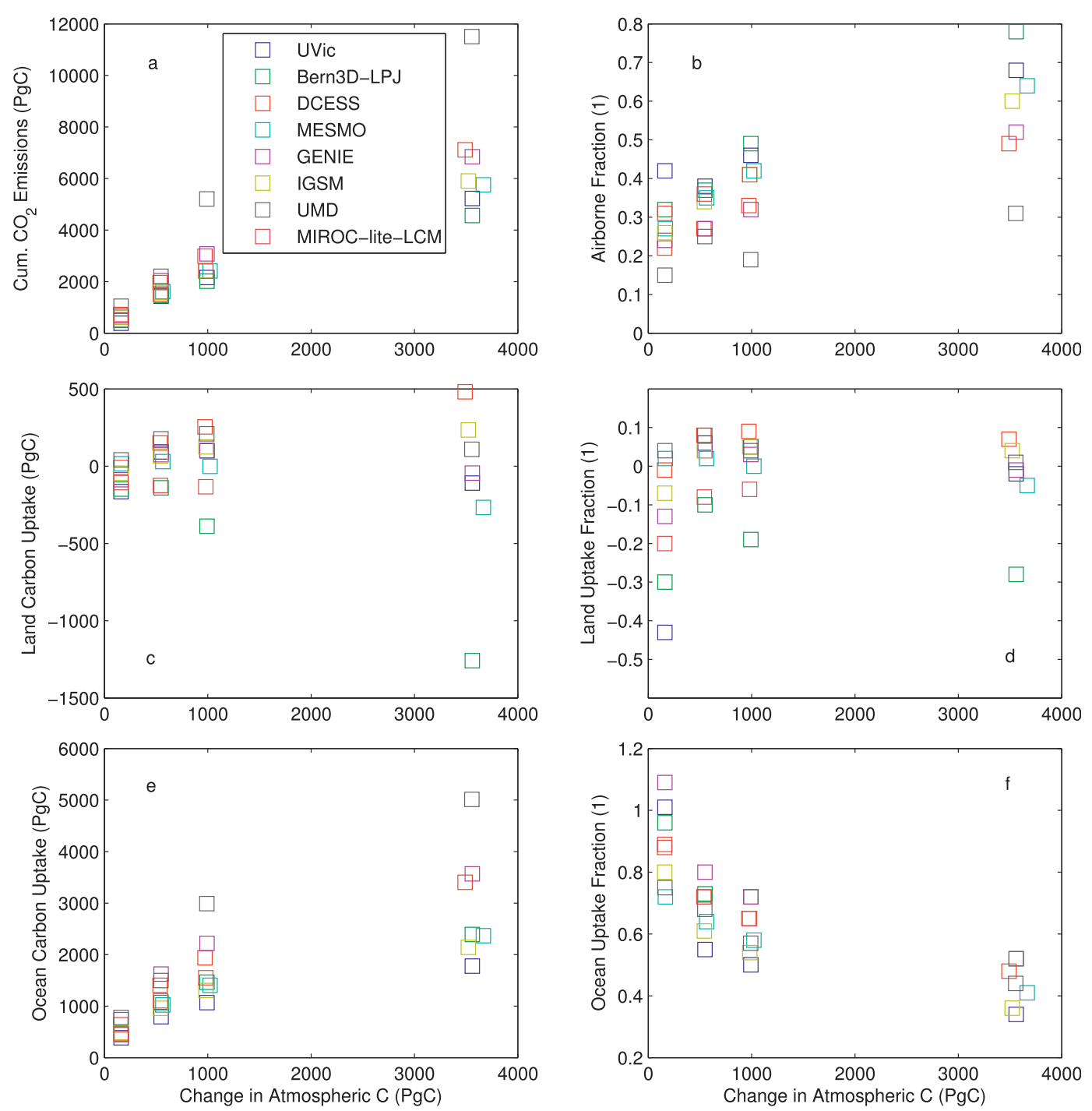

FIG. 5. Changes in carbon inventories by the year 3000 as a function of the change in atmospheric carbon between 1850 and 3000 for RCPs 2.6-8.5: (a) cumulative carbon emissions since 1850, (b) airborne fraction of cumulative emissions, (c) land carbon uptake since 1850, (d) land uptake fraction, (e) ocean carbon uptake since 1850, and (f) ocean uptake fraction.

a range as large as 4500-11500 $\mathrm{PgC}$ for $\mathrm{RCP} 8.5$. Cumulative emissions at the upper end of this range are close to estimates of the carbon bound in the total fossil fuel resource base [9500-15600 PgC; Johansson et al. (2012)].

The airborne fraction increases with increasing atmospheric $\mathrm{CO}_{2}$, from a model ensemble mean of 0.27 for RCP2.6 to 0.57 for RCP8.5. The increase in airborne fraction with $\mathrm{CO}_{2}$ is mostly a result of the decreasing ocean uptake fraction. Ocean carbon uptake is largely driven by atmospheric $\mathrm{CO}_{2}$, with the lowest cumulative uptake occurring in RCP2.6 and the largest in RCP8.5. The ocean uptake fraction decreases significantly with higher $\mathrm{CO}_{2}$ in all models, from an ensemble mean value of 0.89 in RCP2.6 to 0.44 in RCP8.5. The decrease in ocean uptake fraction is due to nonlinear ocean carbonate chemistry and stronger climate-carbon cycle feedbacks at higher atmospheric $\mathrm{CO}_{2}$ (Friedlingstein et al. 2006; Plattner et al. 2008).

The results for land carbon uptake are more complex, as they vary significantly across models and scenarios. In RCPs 4.5 and 6.0, the terrestrial biosphere takes up carbon between 2000 and the year of $\mathrm{CO}_{2}$ stabilization in all models (not shown). In RCP8.5, the terrestrial biosphere initially takes up $\mathrm{CO}_{2}$ but becomes a $\mathrm{CO}_{2}$ source after about a century in most models. The Bern3D-LPJ exhibits negligible land uptake even in the first $100 \mathrm{yr}$ of the RCP8.5 simulation. After $\mathrm{CO}_{2}$ stabilization, the land response ranges from strong emissions (Bern3D-LPJ) to 
weak uptake (UVic) under all RCPs (not shown). RCP differences in land carbon uptake during the twenty-first century result from different strengths of carbon cycle feedbacks, but also from differences in land cover change. For instance, RCPs 4.5 and 6.0 include reforestation, while RCPs 2.6 and 8.5 assume substantial deforestation.

The behavior of land carbon uptake at 3000 as a function of atmospheric $\mathrm{CO}_{2}$ varies strongly across models: while some EMICs simulate an increase in land uptake with increasing $\mathrm{CO}_{2}$ (e.g., DCESS), others simulate a strong decrease (Bern3D-LPJ; Fig. 5c). Bern3D-LPJ has the highest sensitivity of land carbon uptake to temperature (Eby et al. 2013), as it includes a representation of carbon release from permafrost soils and peatlands. The land uptake fraction increases from $\mathrm{RCP} 2.6$ to RCP4.5 in most models, and remains approximately constant or decreases from RCP4.5 to RCP8.5 (the ensemble mean land uptake fraction remains approximately constant across RCPs). The low land uptake fraction under RCP2.6 in some models may be due to relatively large LUC emissions (Arora et al. 2011).

Our results differ from those of a previous EMIC intercomparison (Plattner et al. 2008), which found that the fractional distribution of excess carbon among the atmosphere, ocean, and terrestrial biosphere remained approximately constant across scenarios. That study, however, considered a much narrower range in atmospheric $\mathrm{CO}_{2}$ changes $(\sim 700-1000 \mathrm{PgC})$.

\section{c. Preindustrial $\mathrm{CO}_{2}$ emission commitment}

Preindustrial $\mathrm{CO}_{2}$ emission commitment (PIEM- $\left.\mathrm{CO}_{2}\right)$ is investigated by setting the anthropogenic $\mathrm{CO}_{2}$ emission perturbation to zero after 2300 and letting the atmospheric $\mathrm{CO}_{2}$ concentration evolve freely. Non- $\mathrm{CO}_{2}$ radiative forcing is held constant at year-2300 levels. These simulations were performed by EMICs with an interactive carbon cycle only. As discussed in section $2 b$, setting the anthropogenic perturbation to zero does not result in zero emissions exactly: decadal-mean $\mathrm{CO}_{2}$ emissions after 2300 range from -0.5 to $0.5 \mathrm{PgC} \mathrm{yr}^{-1}$ for all RCPs (Fig. 6). $\mathrm{CO}_{2}$ emissions are $\leq 0$ in all models, except for the UMD model. The long-term effect of these annual emissions is evident in Fig. 7 for the RCP2.6 PIEM- $\mathrm{CO}_{2}$ commitment simulation, with cumulative emissions declining between 2300 and 3000 (with exception of the UMD model, for which cumulative emissions increase). Note that despite the slightly different model setup, the PIEM-CO ${ }_{2}$ commitment simulations are comparable to the zero- $\mathrm{CO}_{2}$-emission commitment simulations discussed in the literature.

As $\mathrm{CO}_{2}$ emissions nearly cease, atmospheric $\mathrm{CO}_{2}$ declines as the ocean and land continue to absorb carbon from the atmosphere (Fig. 6). The efficacy of carbon uptake differs between models and so does the rate of decline of atmospheric $\mathrm{CO}_{2}$. By the year 3000, atmospheric $\mathrm{CO}_{2}$ is still far away from a new equilibrium because of the long time scales of $\mathrm{CO}_{2}$ removal from the atmosphere (Eby et al. 2009). By 3000, the ensemble mean atmospheric $\mathrm{CO}_{2}$ is $330 \mathrm{ppmv}$ in RCP2.6, $440 \mathrm{ppmv}$ in RCP4.5, 590 ppmv in RCP6.0, and 1560 ppmv in RCP8.5. Note that the upper boundary of the atmospheric $\mathrm{CO}_{2}$ range spanned by models increases after 2300 . The upper limit is set by the UMD model, which has slightly positive $\mathrm{CO}_{2}$ emissions. Atmospheric $\mathrm{CO}_{2}$ at 3000 in RCPs 4.5-8.5 is still at a high fraction $(\geq 0.5)$ of the peak atmospheric $\mathrm{CO}_{2}$ in all models (Fig. 8). These results are consistent with previous studies (Montenegro et al. 2007; Archer and Brovkin 2008; Plattner et al. 2008; Eby et al. 2009; Solomon et al. 2009; Archer et al. 2009), which showed that a significant fraction of $\mathrm{CO}_{2}$ remains airborne after several hundred years, and that this fraction increases with higher $\mathrm{CO}_{2}$ concentrations (or emissions).

Despite decreasing radiative forcing after 2300 in most models, global mean temperature decreases only slightly in RCPs $4.5-6.0$ between 2300 and 3000 and remains approximately constant in RCP8.5 (Table 4). This near constancy of global mean temperature after elimination of anthropogenic $\mathrm{CO}_{2}$ emissions is known from earlier studies with EMICs and complex ESMs (Matthews and Caldeira 2008; Plattner et al. 2008; Eby et al. 2009; Solomon et al. 2009; Lowe et al. 2009; Frölicher and Joos 2010; Gillett et al. 2011; Zickfeld et al. 2012) and results from the cancellation of two opposing effects: the delayed warming due to ocean thermal inertia and the decrease in radiative forcing associated with declining atmospheric $\mathrm{CO}_{2}$ levels in conjunction with the logarithmic dependence of forcing on atmospheric $\mathrm{CO}_{2}$ (Eby et al. 2009; Solomon et al. 2010). At 3000, the fraction of warming that persists relative to that in the year 2300 (the year the anthropogenic perturbation is set to zero, which approximately corresponds to the year of peak warming) is 0.85 , 0.89 , and 0.99 in the ensemble mean for RCPs 4.5, 6.0, and 8.5 respectively (Fig. 8). These values are consistent with those from Eby et al. (2009), who found that $80 \%-100 \%$ of the warming anomaly persists 700 years after emissions were eliminated, with the fraction increasing with the amount of cumulative emissions.

In contrast to global mean temperature, sea level rise due to thermal expansion continues after elimination of anthropogenic $\mathrm{CO}_{2}$ emissions in RCPs 4.5-8.5. The sea level rise between 2300 and 3000 is substantial in these scenarios (Table 4) and comparable to the sea level rise between 1850 and 2300. While sea level rise in some EMICs levels off toward the end of the simulation, it continues to rise in others. This is consistent with the 

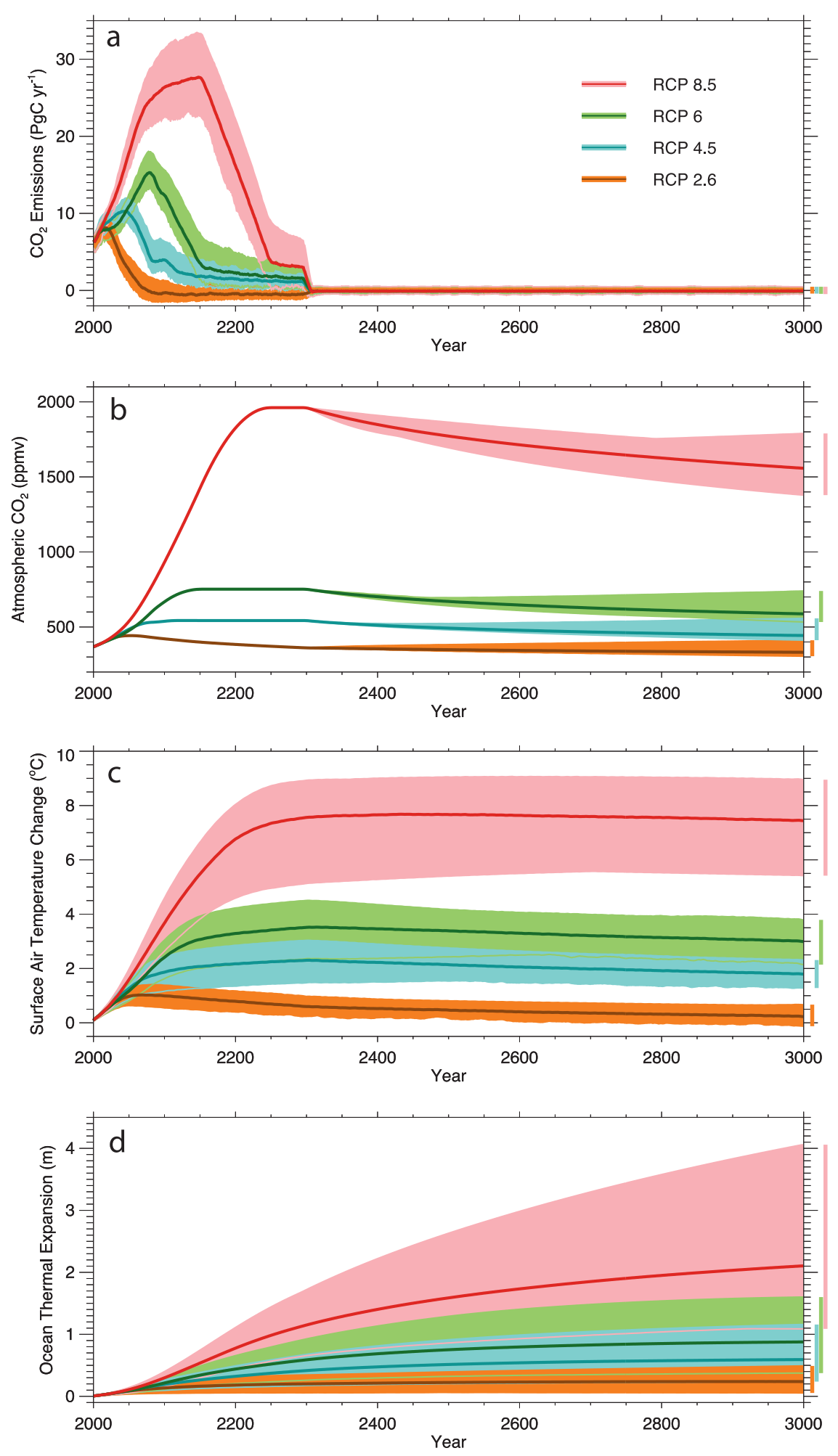

FIG. 6. Time evolution of climate variables for the PIEM- $\mathrm{CO}_{2}$ commitment simulations under four RCP scenarios: (a) diagnosed cumulative $\mathrm{CO}_{2}$ emissions since 1850, (b) atmospheric $\mathrm{CO}_{2}$, (c) surface air temperature change, and (d) ocean thermal expansion. Anomalies are relative to 1986-2005. Shown are the model ensemble averages (thick solid lines), the ranges spanned by all models (shaded domains, delimited by thin solid lines), and the range in the year 3000 (vertical bars on right side). Data were smoothed using a 10-yr moving average. 

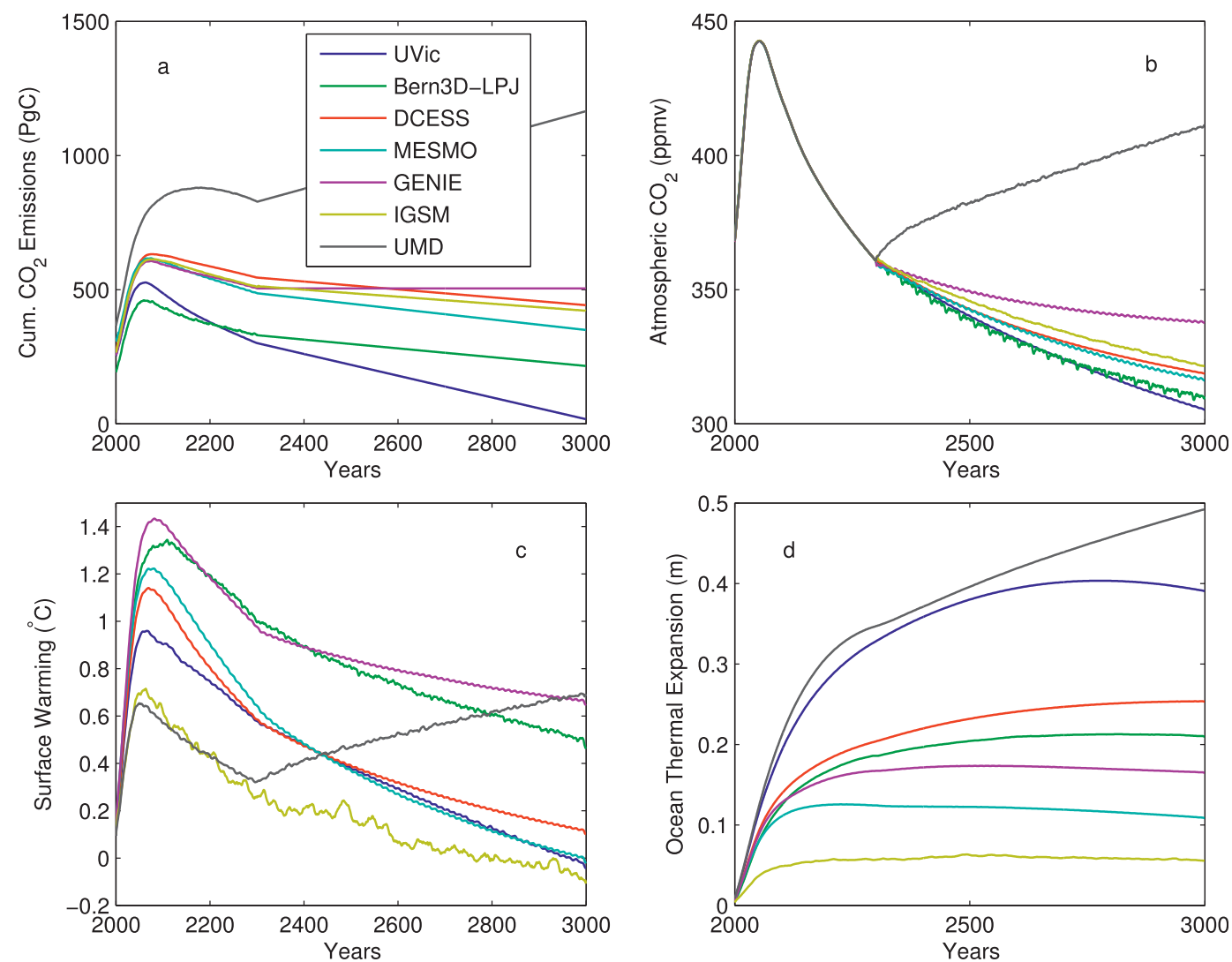

FIG. 7. RCP2.6 PIEM-CO $\mathrm{CO}_{2}$ commitment simulations: (a) cumulative $\mathrm{CO}_{2}$ emissions since 1850, (b) atmospheric $\mathrm{CO}_{2}$, (c) surface air temperature change, and (d) ocean thermal expansion. Anomalies in (c) and (d) are relative to 1986-2005. Data in (c) were smoothed using a 10-yr moving average. Note that the response of the UMD model differs from that of other models resulting from slightly positive $\mathrm{CO}_{2}$ emissions after year 2300 .

results of a previous EMIC intercomparison (Plattner et al. 2008). In zero-emission commitment simulations with a complex ESM, Gillett et al. (2011) found thermosteric sea level to still rise 900 years after cessation of emissions. Given that surface air temperature remains elevated for centuries to millennia and intermediate-depth temperature in the high-latitude Southern Ocean continues to warm, potentially leading to a collapse of the West Antarctic Ice Sheet (Gillett et al. 2011), thermal expansion on these time scales is likely to be compounded by large sea level contributions from disintegrating ice sheets.

Both global mean warming and sea level rise behave differently in RCP2.6 than in the higher scenarios (Fig. 7). Because of the strong decline in atmospheric $\mathrm{CO}_{2}$ and, accordingly, radiative forcing already before 2300 , the warming and sea level rise commitment after 2300 are lower in this scenario. Global mean temperature continues to decrease between 2300 and 3000 and sea level stabilizes or even starts to slightly drop in some models (except for the UMD model, for which atmospheric $\mathrm{CO}_{2}$ increases after 2300).
An interesting question in view of the comparability of results from different studies is whether the preindustrial (or zero) $\mathrm{CO}_{2}$ emission commitment is dependent on the time $\mathrm{CO}_{2}$ emissions cease. We address this question by comparing the temperature and thermal expansion commitment in PIEM- $\mathrm{CO}_{2}$ simulations with those in the reversibility simulations (REc) with constant year-2300 radiative forcing to the year 3000 and zero $\mathrm{CO}_{2}$ emissions thereafter. If $\mathrm{CO}_{2}$ emissions cease earlier (e.g., in 2300 as opposed to 3000), the system is further away from equilibrium with the stabilized radiative forcing, the fraction of realized warming is smaller (Fig. 2b), and one would expect a larger temperature and thermal expansion commitment. One complicating factor in our comparison is that the PIEM-CO $\mathrm{CO}_{2}$ simulations entail slightly negative (as opposed to zero) emissions in most models, leading to a more rapid decline in atmospheric $\mathrm{CO}_{2}$ and hence radiative forcing after cessation of emissions. The model average decrease in surface air temperature after emissions cease is lower in the REc than in the PIEM-CO simulations $\left(-0.2^{\circ} \mathrm{C}\right.$ versus $-0.5^{\circ} \mathrm{C}$ for RCPs 4.5 and 6.0$)$, 

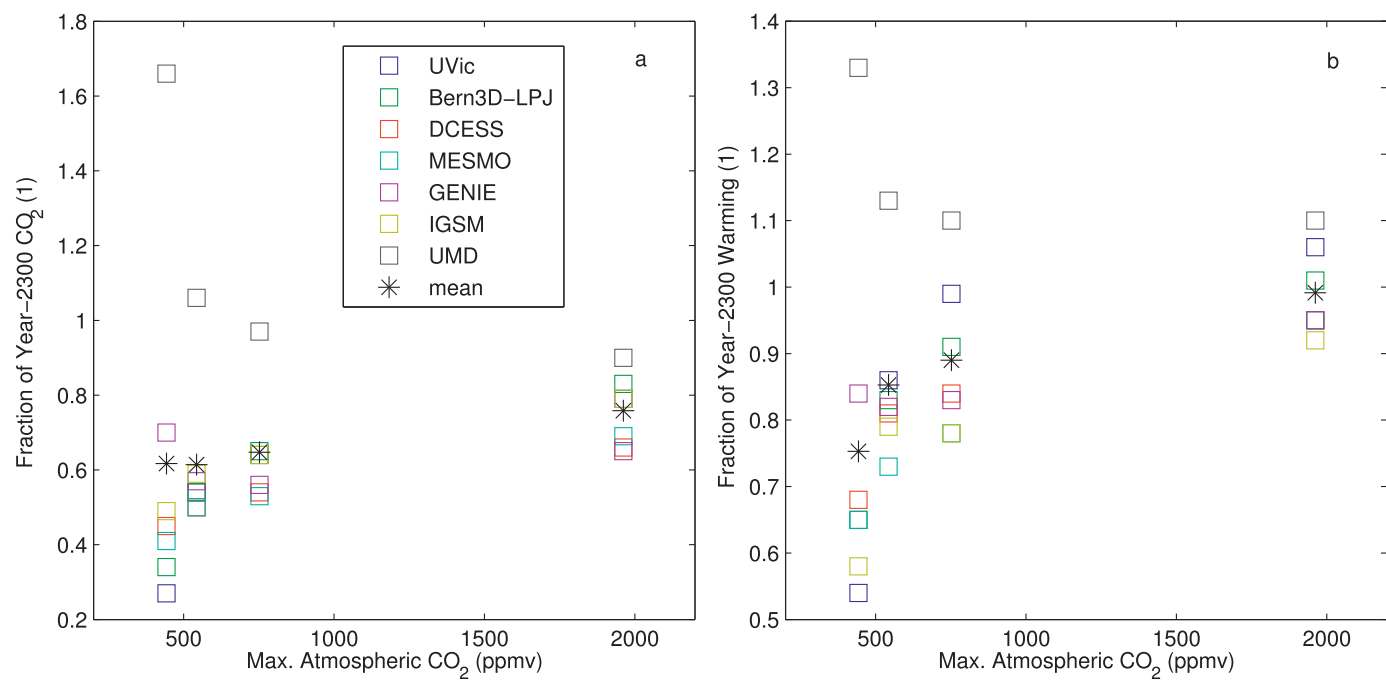

FIG. 8. PIEM-CO 2 simulations for RCPs 2.6-8.5. (a) Atmospheric $\mathrm{CO}_{2}$ in year 3000 as a fraction of atmospheric $\mathrm{CO}_{2}$ in year 2300 (corresponding to peak atmospheric $\mathrm{CO}_{2}$ in RCPs 4.5-8.5). (b) Warming in year 3000 as a fraction of warming in year 2300 (corresponding approximately to peak warming in RCPs 4.5-8.5). Results are shown as a function of the peak atmospheric $\mathrm{CO}_{2}$ concentration in each RCP, which is the same for all models.

which we attribute to the slower decline in radiative forcing in the REc simulations. On the other hand, the thermal expansion commitment is larger in the PIEM$\mathrm{CO}_{2}$ simulations $(0.3 \mathrm{~m}$ versus $0.1 \mathrm{~m}$ in the $\mathrm{REc}$ simulation for RCP6.0), consistent with the smaller fraction of realized warming at the time emissions cease. These results indicate that the temperature commitment is determined largely by the radiative forcing after emissions cease, whereas the thermal expansion commitment is determined by the radiative forcing before emissions cease, consistent with the longer response time scale of the deep ocean.

\section{d. Preindustrial emission commitment}

The PIEM simulations are similar to the PIEM-CO simulations described in the previous paragraph, except that non- $\mathrm{CO}_{2}$ radiative forcing is abruptly set to zero in the year 2300 . Note that this is different from setting emissions of non- $\mathrm{CO}_{2}$ gases to zero because the finite atmospheric lifetime of these gases would lead to a gradual decline in their concentration and associated radiative forcing (except for aerosols, which have a very short atmospheric residence time). Similar to the PIEM-CO ${ }_{2}$ runs, atmospheric $\mathrm{CO}_{2}$ declines after 2300 under all RCPs (Fig. 9). The rate of decrease is slightly larger than in the PIEM- $\mathrm{CO}_{2}$ simulations as a result of the greater efficiency of the carbon sinks in a slightly cooler climate (i.e., a reduced climate-carbon cycle feedback). The surface temperature decreases abruptly around 2300 and more gradually thereafter, with a rate similar to that in the PIEM- $\mathrm{CO}_{2}$ simulations. Accordingly, the warming commitment after 2300 is more negative than in the PIEM-CO runs (Table 4). Note that the temperature response in the simulations described here is different from that projected in simulations where all anthropogenic emissions are set to zero (Hare and Meinshausen 2006; Armour and Roe

TABLE 4. Projected global mean warming and thermosteric sea level rise between 2300 and 3000 in CEM, CCO, $\mathrm{PIEM}-\mathrm{CO}_{2}$, and $\mathrm{PIEM}$ commitment simulations. Given are model ensemble means and model ranges in parentheses.

\begin{tabular}{lcccc}
\hline \hline Scenario & CEM & CCO & PIEM-CO 2 & PIEM \\
\hline & & Warming commitment $\left({ }^{\circ} \mathrm{C}\right)$ & $-0.4(-0.7,0.4)$ & $-0.8(-1.2,0.4)$ \\
RCP2.6 & $-0.8(-1.0,-0.4)$ & $0.0(-0.1,0.1)$ & $-0.5(-1.0,0.3)$ & $-1.2(-1.8,0.3)$ \\
RCP4.5 & $0.8(0.5,1.3)$ & $0.3(0.0,0.6)$ & $-0.5(-1.2,0.4)$ & $-1.2(-2.0,0.4)$ \\
RCP6.0 & $1.1(0.7,1.4)$ & $0.4(0.0,0.9)$ & $-0.1(-0.7,0.6)$ & $-1.3(-2.3,0.6)$ \\
RCP8.5 & $1.3(0.7,1.7)$ & $0.7(0.0,1.2)$ & Thermal expansion commitment $(\mathrm{m})$ & $-0.03(-0.09,0.15)$ \\
& & $0.11(0.03,0.32)$ & $0.04(-0.02,0.15)$ & $0.08(-0.08,0.34)$ \\
RCP2.6 & $-0.04(-0.10,0.02)$ & $0.38(0.12,0.95)$ & $0.18(0.02,0.49)$ & $0.16(-0.07,0.47)$ \\
RCP4.5 & $0.40(0.16,0.83)$ & $0.57(0.20,1.34)$ & $0.29(0.04,0.69)$ & $0.66(0.03,1.69)$ \\
RCP6.0 & $0.60(0.24,1.19)$ & $1.31(0.38,2.64)$ & $0.97(0.22,2.37)$ & \\
RCP8.5 & $1.30(0.41,2.84)$ & & &
\end{tabular}



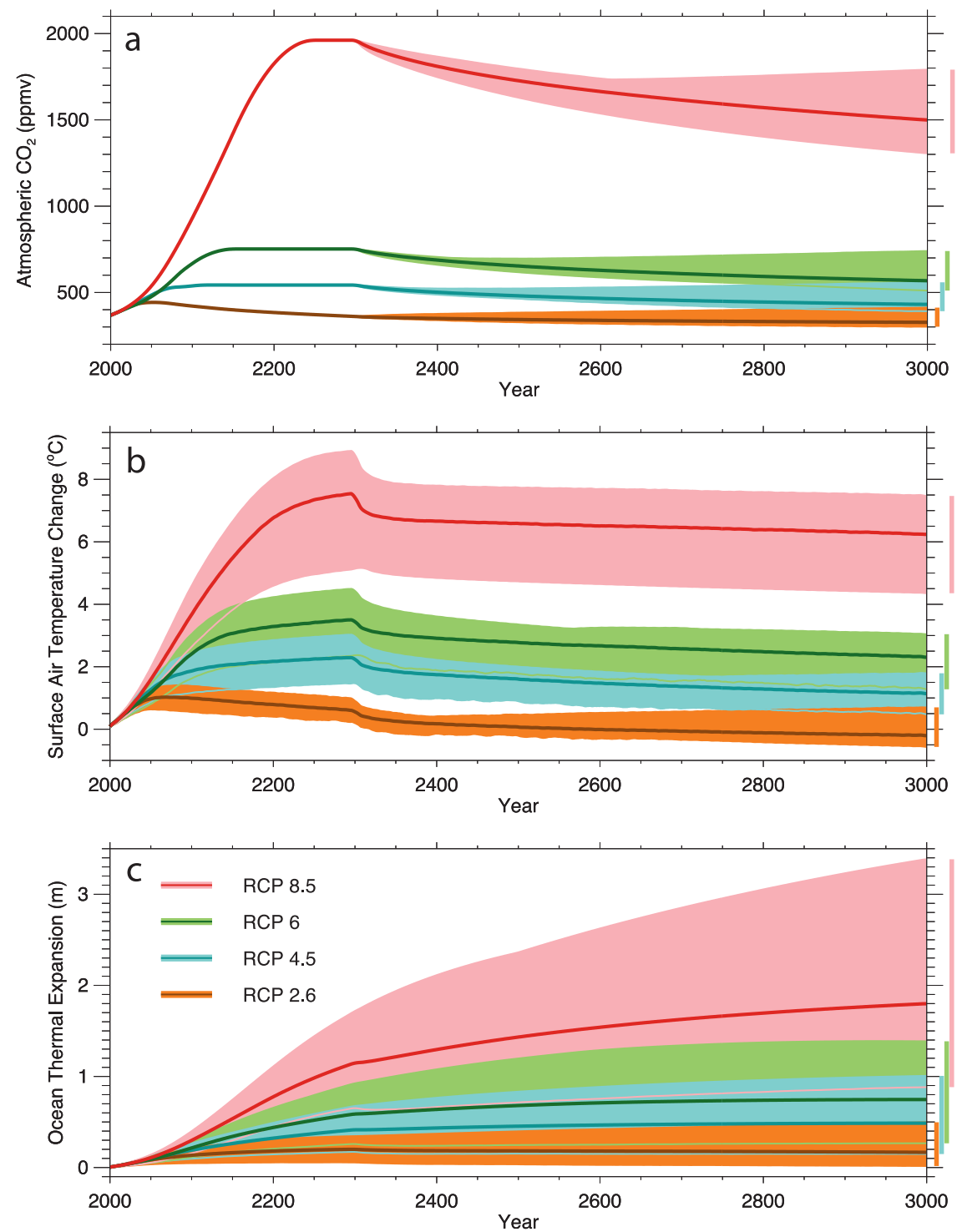

FIG. 9. Time evolution of climate variables for the PIEM commitment simulations under four RCP scenarios: (a) atmospheric $\mathrm{CO}_{2}$, (b) surface air temperature change, and (c) ocean thermal expansion. Anomalies are relative to 1986-2005. Shown are the model ensemble averages (thick solid lines), the ranges spanned by all models (shaded domains, delimited by thin solid lines), and the range in the year 3000 (vertical bars on right side). Data were smoothed using a 10-yr moving average.

2011; Matthews and Zickfeld 2012). In those simulations, temperature increases temporarily after elimination of emissions due to the removal of the negative radiative forcing from aerosols (Hare and Meinshausen 2006; Armour and Roe 2011; Matthews and Zickfeld 2012). In the RCPs used in the present study, the year-2300 non$\mathrm{CO}_{2}$ radiative forcing is dominated by the positive forcing from non- $\mathrm{CO}_{2}$ greenhouse gases such that a removal of this forcing leads to a sudden cooling. The sea level rise commitment in PIEM simulations is smaller than in
PIEM-CO $\mathrm{CO}_{2}$ simulations (Table 4), consistent with the more rapid decline in radiative forcing.

\section{e. Constant emission commitment}

The CEM commitment simulations differ from the simulations described previously in that $\mathrm{CO}_{2}$ emissions are held constant at significant positive values after 2300 in RCPs 4.5-8.5 (range of 0.8-6.4 $\mathrm{PgC} \mathrm{yr}^{-1}$; Fig. 10). Since only a fraction of these $\mathrm{CO}_{2}$ emissions is taken up by carbon sinks, atmospheric $\mathrm{CO}_{2}$ increases again after 
2300 (as opposed to remaining constant or decreasing as in the other commitment simulations). As a result, surface air temperature continues to increase, with a significant positive warming commitment after 2300 (Table 4). Thermosteric sea level also continues to rise after 2300 , with the sea level rise between 2300 and 3000 being several factors larger than that realized by 2300 (Table 4).

The climate response in the RCP2.6 CEM simulation is very different from that under the higher RCPs: $\mathrm{CO}_{2}$ emissions in the year 2300 are slightly negative in all

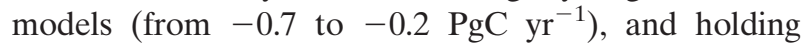
emissions fixed at these values results in a continuing decrease in atmospheric $\mathrm{CO}_{2}$. Accordingly, global mean temperature continues to decrease, and sea level starts to fall between 2300 and 3000 in all models. The ensemble mean warming and sea level rise commitments are slightly more negative than to those in the RCP2.6 PIEM commitment simulations (Table 4).

\section{f. Climate change reversibility}

To explore under which conditions the climate system can revert to its preindustrial state, a set of "reversibility" simulations was carried out. These simulations were started from the year-3000 state of the CCO simulations. Two simulations were performed with atmospheric $\mathrm{CO}_{2}$ decreasing linearly to zero (ramp) over a period of 100 $1000 \mathrm{yr}$, respectively. These scenarios are highly idealized and are used for illustrative purpose only. Since the atmospheric $\mathrm{CO}_{2}$ changes are externally prescribed, these simulations give insight into the reversibility of the physical climate system. A third simulation, in which atmospheric $\mathrm{CO}_{2}$ is allowed to evolve freely after emissions are set to zero, is aimed at exploring the reversibility of changes in the coupled climate-carbon cycle system. It should be noted that non- $\mathrm{CO}_{2}$ forcing after year 3000 is held fixed at slightly positive values and therefore the total forcing after ramp down of atmospheric $\mathrm{CO}_{2}$ to preindustrial levels is different from zero.

With atmospheric $\mathrm{CO}_{2}$ decreasing to preindustrial levels over a period of $100 \mathrm{yr}$, surface air temperature decreases rapidly at first (during the $\mathrm{CO}_{2}$ ramp-down phase) and more slowly thereafter (Fig. 11). At the year 4000 surface air temperature is still higher than under 1851-60 conditions (Table 5). This remaining warming 900 years after atmospheric $\mathrm{CO}_{2}$ returned to preindustrial levels can be explained by the thermal inertia of the climate system, which plays out both during periods of warming and cooling, and the (small) residual positive radiative forcing from non- $\mathrm{CO}_{2}$ sources.

The thermosteric sea level rise trend is also reversed with decreasing atmospheric $\mathrm{CO}_{2}$. Rates of sea level fall, however, are slower than rates of cooling, and sea level is significantly higher than under preindustrial conditions at year 4000 (Table 5). The thermohaline circulation exhibits a rapid strengthening in the ensemble mean during the $\mathrm{CO}_{2}$ decrease phase, with the overturning first overshooting and then slowly converging to preindustrial values. Note that under RCP8.5 the thermohaline circulation is close to collapse in the Bern3D-LPJ model, but recovers after the ramp down of atmospheric $\mathrm{CO}_{2}$.

In the simulations with a slower decrease of atmospheric $\mathrm{CO}_{2}$ (over $1000 \mathrm{yr}$ ), surface air temperature also starts to drop after the year 3000 , but the cooling is more gradual than in the 100 -yr ramp-down experiment (Fig. 12). Also, the rate of cooling is lower during the first 500 years of the ramp down than during the last 500 years. This nonlinear response can again be explained with the thermal inertia of the climate system: despite 700 years of constant forcing (from 2300 to 3000) the climate system is still equilibrating with that forcing, and the associated warming commitment acts to offset the cooling because of decreasing $\mathrm{CO}_{2}$ levels during the first few hundred years of the $\mathrm{CO}_{2}$ ramp-down phase. Surface air temperature at 4000 is warmer than in the simulations with a $100-y r$ ramp down, particularly for the higher RCPs (Table 5).

In contrast to temperature, thermosteric sea level continues to rise for several centuries after $\mathrm{CO}_{2}$ starts to decrease. For instance, ensemble mean sea level does not peak until the year 3200 under RCP6.0 and 3300 under RCP8.5. Year-4000 sea level rise is about twice as high in these simulations as in the 100-yr rampdown experiments (Table 5). The thermohaline circulation recovers slowly at first and more rapidly toward the end of the $\mathrm{CO}_{2}$ decrease phase. Under RCPs 4.58.5 the ensemble-mean overturning at year 4000 exceeds the preindustrial value. Individual models deviate substantially from the ensemble-mean behavior. For instance, overturning in the Bern3D-LPJ model does not recover under declining $\mathrm{CO}_{2}$ levels, but collapses completely around the year 3500 .

In the third reversibility experiment, atmospheric $\mathrm{CO}_{2}$ is allowed to evolve freely after the year 3000 (under zero $\mathrm{CO}_{2}$ emissions). This simulation was performed by a subset of EMICs with an interactive carbon cycle only. It is similar to the PIEM-CO $\mathrm{C}_{2}$ simulation, except that a 700-yr $\mathrm{CO}_{2}$ stabilization phase precedes the free-evolving$\mathrm{CO}_{2}$ phase (and emissions are exactly zero as opposed to slightly negative in the PIEM-CO $\mathrm{CO}_{2}$ experiments). Following the cessation of $\mathrm{CO}_{2}$ emissions, atmospheric $\mathrm{CO}_{2}$ declines because of $\mathrm{CO}_{2}$ uptake by marine and terrestrial carbon sinks (Fig. 13). As discussed earlier for the PIEM- $\mathrm{CO}_{2}$ experiments, surface air temperature remains approximately constant after elimination of $\mathrm{CO}_{2}$ emissions, while sea level continues to rise. Compared to the reversibility experiments with $\mathrm{CO}_{2}$ ramp down, surface air 

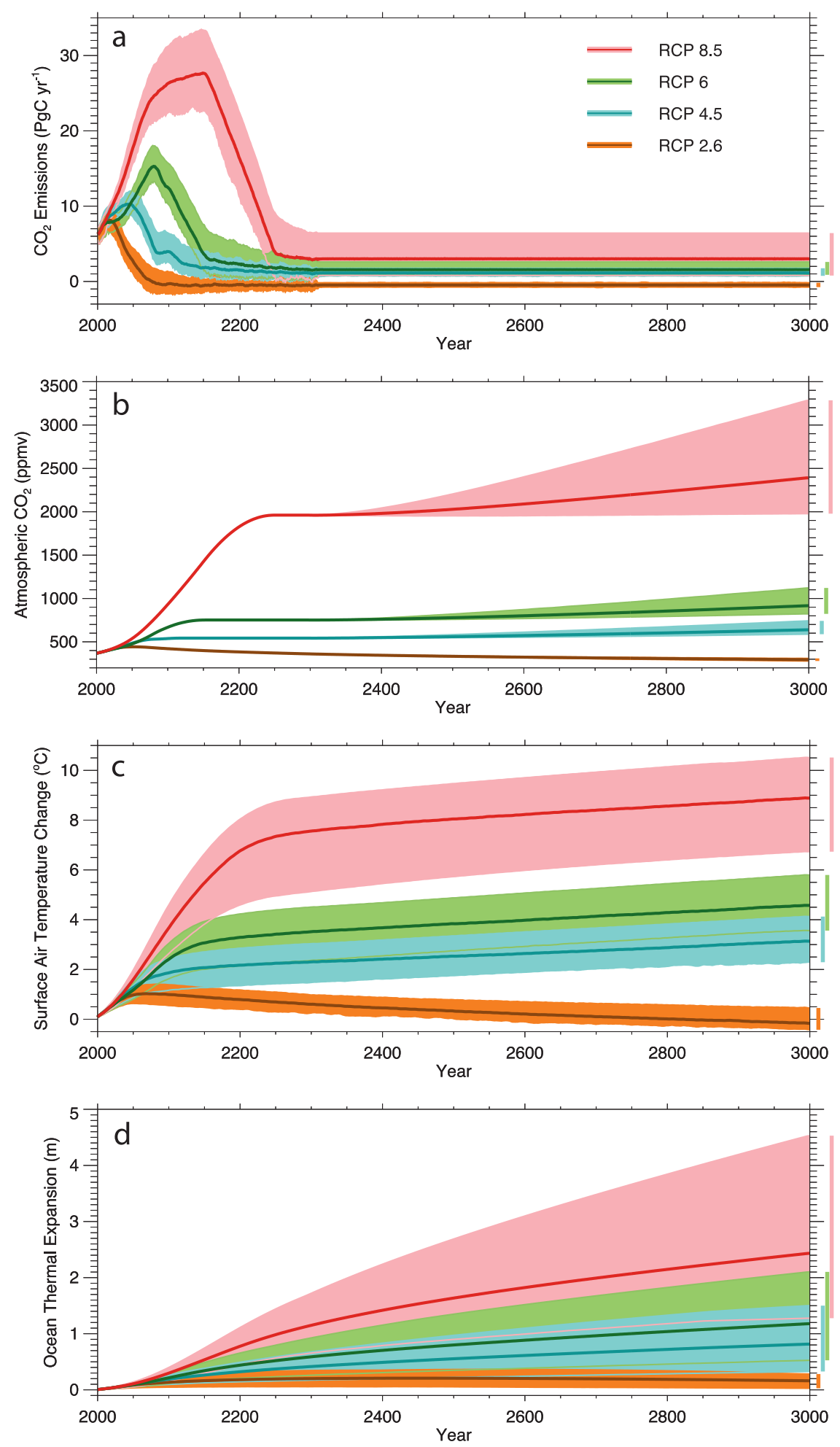

FIG. 10. Time evolution of climate variables for the CEM commitment simulations under four RCP scenarios: (a) diagnosed $\mathrm{CO}_{2}$ emissions, (b) atmospheric $\mathrm{CO}_{2}$, (c) surface air temperature change, and (d) ocean thermal expansion. Anomalies in (c) and (d) are relative to 1986-2005. Shown are the model ensemble averages (thick solid lines), the ranges spanned by all models (shaded domains, delimited by thin solid lines), and the range in the year 3000 (vertical bars on right side). Data were smoothed using a 10-yr moving average. 

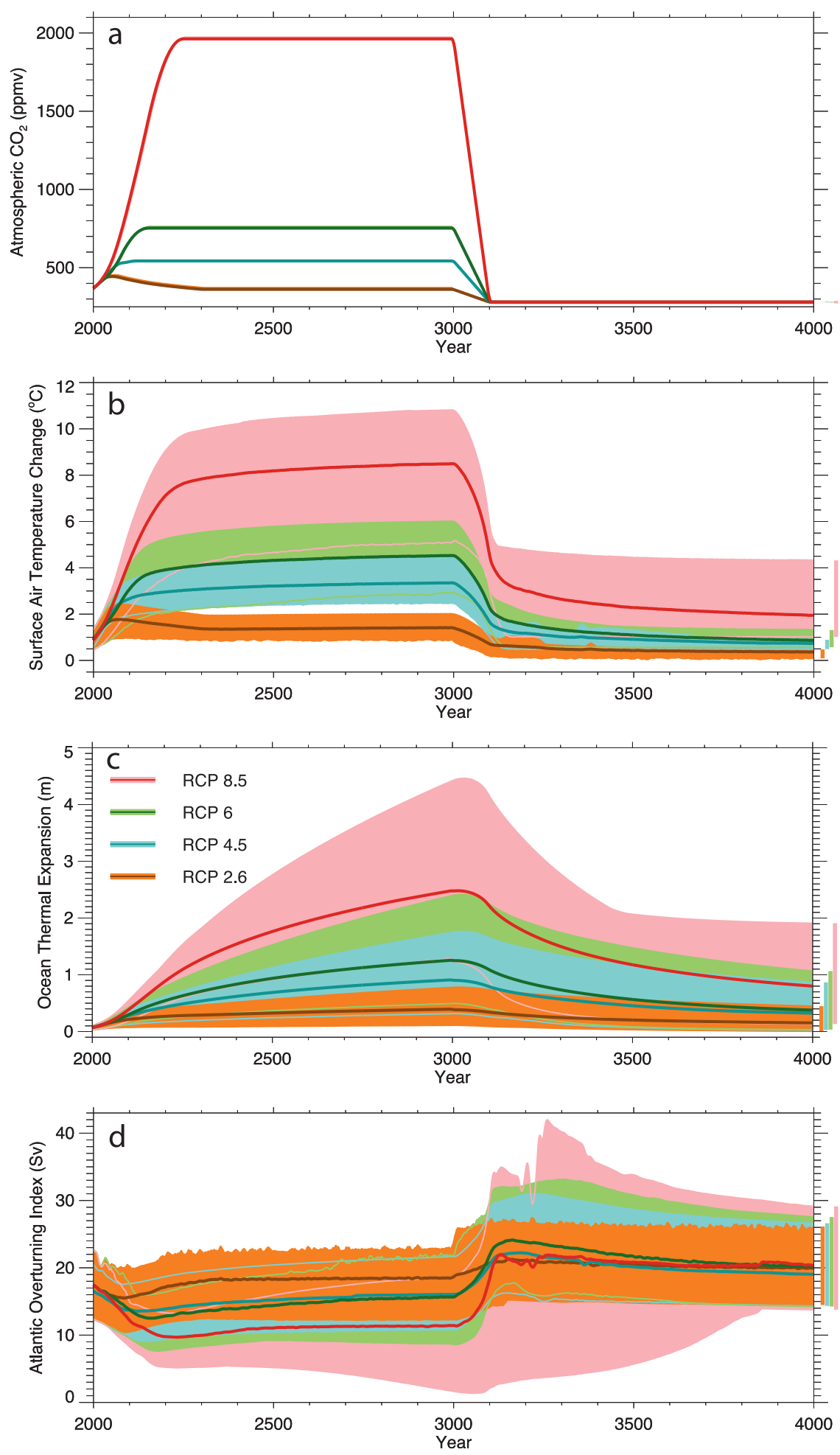

FIG. 11. Time evolution of climate variables for REa simulations with atmospheric $\mathrm{CO}_{2}$ after year 3000 decreasing to preindustrial levels over $100 \mathrm{yr}$ : (a) atmospheric $\mathrm{CO}_{2}$, (b) surface air temperature change, (c) ocean thermal expansion, and (d) Atlantic overturning index (maximum of the overturning streamfunction in the North Atlantic). Anomalies in (b) and (c) are relative to preindustrial (1851-60). Shown are the model ensemble averages (thick solid lines), the ranges spanned by all models (shaded domains, delimited by thin solid lines), and the range in the year 3000 (vertical bars on side). Data were smoothed using a 10-yr moving average. 
TABLE 5. Warming and thermosteric sea level in 3991-4000 relative to $1851-60$ for climate reversibility simulations with a 100-yr ramp down of atmospheric $\mathrm{CO}_{2}$ after the year 3000 (REa), a 1000-yr ramp down of atmospheric $\mathrm{CO}_{2}(\mathrm{REb})$, and freely evolving $\mathrm{CO}_{2}(\mathrm{REc})$. Given are model ensemble means and model ranges in parentheses.

\begin{tabular}{lccc}
\hline \hline Scenario & REa & REb & REc \\
\hline & \multicolumn{3}{c}{ Warming $\left({ }^{\circ} \mathrm{C}\right)$} \\
RCP2.6 & $0.4(0.1,0.5)$ & $0.5(0.1,0.7)$ & $1.3(0.7,1.8)$ \\
RCP4.5 & $0.7(0.5,0.9)$ & $1.1(0.6,1.4)$ & $3.2(2.2,4.0)$ \\
RCP6.0 & $0.9(0.6,1.3)$ & $1.4(0.7,1.9)$ & $4.5(3.4,5.3)$ \\
RCP8.5 & $2.0(1.1,4.3)$ & $3.1(1.5,4.6)$ & $8.9(6.7,10.2)$ \\
& \multicolumn{3}{c}{ Thermal expansion $(\mathrm{m})$} \\
RCP2.6 & $0.2(0.05,0.4)$ & $0.3(0.1,0.7)$ & $0.4(0.1,0.8)$ \\
RCP4.5 & $0.3(0.1,0.9)$ & $0.5(0.2,1.5)$ & $0.8(0.4,1.6)$ \\
RCP6.0 & $0.4(0.1,1.1)$ & $0.8(0.3,2.0)$ & $1.2(0.6,2.4)$ \\
RCP8.5 & $0.8(0.2,1.9)$ & $1.9(0.5,3.5)$ & $2.9(1.3,6.3)$ \\
\hline
\end{tabular}

temperature and sea level rise at 4000 are much higher in the free-evolving- $\mathrm{CO}_{2}$ case (Table 5). Similarly to surface air temperature, the thermohaline circulation remains approximately constant after emissions cease. An exception is again the overturning in the Bern3D-LPJ model, which collapses completely by the year 3200 .

EMICs with an interactive carbon cycle were used to diagnose the $\mathrm{CO}_{2}$ emissions compatible with the $\mathrm{CO}_{2}$ concentration trajectories for the two reversibility experiments with $\mathrm{CO}_{2}$ ramp down (Fig. 14). The abrupt decrease of atmospheric $\mathrm{CO}_{2}$ in the two experiments (Figs. 11a, 12a) requires emissions to become negative to close the $\mathrm{CO}_{2}$ budget. Emissions are much more negative in the experiments with a fast (100 yr) ramp down than in those with a slower (1000 yr) ramp down, particularly under the higher RCPs. For each experiment, the larger the rate of atmospheric $\mathrm{CO}_{2}$ decline, the more negative the diagnosed $\mathrm{CO}_{2}$ emissions.

Negative emissions imply that the prescribed rate of atmospheric $\mathrm{CO}_{2}$ decline exceeds the uptake capacity of the marine and terrestrial carbon sinks. In the 100-yr ramp-down experiments, terrestrial carbon inventories decline strongly during the $\mathrm{CO}_{2}$ decrease phase, and remain relatively stable thereafter in all models (Fig. 15). At year 4000, terrestrial carbon inventories are smaller than at preindustrial. The likely reason is the lag of surface air temperature relative to atmospheric $\mathrm{CO}_{2}$, such that the terrestrial biosphere is subject to higher temperatures despite a return to preindustrial $\mathrm{CO}_{2}$ conditions. Ocean carbon inventories also decline during the $\mathrm{CO}_{2}$ ramp-down phase, although more gradually, and continue to decline until the end of the simulation in all models. At year 4000, ocean carbon inventories are higher than at preindustrial in most models.

In the 1000-yr ramp-down experiment, the decline in land carbon inventories in response to declining $\mathrm{CO}_{2}$ levels is more gradual and continues for the duration of the ramp down (not shown). Ocean carbon inventories, on the other hand, continue to increase after the decline in atmospheric $\mathrm{CO}_{2}$ in several models (exceptions are the UVic and UMD models). By year 3500, ocean carbon turns around and starts to decrease in all models. Continuing ocean carbon uptake at the beginning of the ramp-down phase offsets the carbon release from the terrestrial biosphere at first, such that diagnosed $\mathrm{CO}_{2}$ emissions are only slightly negative. Diagnosed emissions become increasingly more negative toward the end of the ramp down as both ocean and land release $\mathrm{CO}_{2}$ into the atmosphere (Fig. 14b).

\section{g. Cumulative emissions compatible with temperature targets}

A last set of simulations was performed with the UVic and Bern3D-LPJ EMICs to explore the cumulative emissions compatible with long-term temperature targets. These simulations used an inverse modeling approach, whereby $\mathrm{CO}_{2}$ emissions compatible with prescribed temperature trajectories were diagnosed (Zickfeld et al. 2009). Figure 16 displays the diagnosed cumulative emissions for temperature trajectories stabilizing at $1.5^{\circ}, 2^{\circ}, 3^{\circ}$, and $4^{\circ} \mathrm{C}$ for the UVic and Bern3D-LPJ EMICs. The temperature trajectories prescribed to the two models are slightly different until the time of temperature stabilization (Fig. 16a). This does not affect the comparability of results, however, since we discuss the cumulative emissions since preindustrial, and the climate response centuries after elimination of emissions is independent of the emission trajectory (Eby et al. 2009; Zickfeld et al. 2009, 2012). Model mean allowable cumulative emissions are $770,1000,1460$, and $1950 \mathrm{PgC}$ for temperature targets of $1.5^{\circ}, 2^{\circ}, 3^{\circ}$, and $4^{\circ} \mathrm{C}$, respectively. These estimates are slightly lower than the allowable cumulative emissions estimated with an earlier version of the UVic model (Zickfeld et al. 2009). The estimate for the $2^{\circ} \mathrm{C}$ target coincides with the value of $1000 \mathrm{PgC}$ from Allen et al. (2009), and is somewhat higher than the value calculated by Meinshausen et al. (2009), who assumed stronger forcing from non- $\mathrm{CO}_{2}$ gases.

Allowable cumulative emissions at 2500 are slightly higher in the Bern3D-LPJ than in the UVic model for the lower temperature targets $\left(1.5^{\circ}-2^{\circ} \mathrm{C}\right)$, whereas they are lower for the highest temperature target $\left(4^{\circ} \mathrm{C}\right)$. Allowable emissions consistent with temperature targets depend on both the physical and biogeochemical model response. For instance, the higher the climate sensitivity and/or the stronger the (positive) climate-carbon cycle feedback, the lower the amount of cumulative emissions consistent with a specified temperature target (Zickfeld et al. 2009). Both EMICs have a relatively high climate sensitivity and 

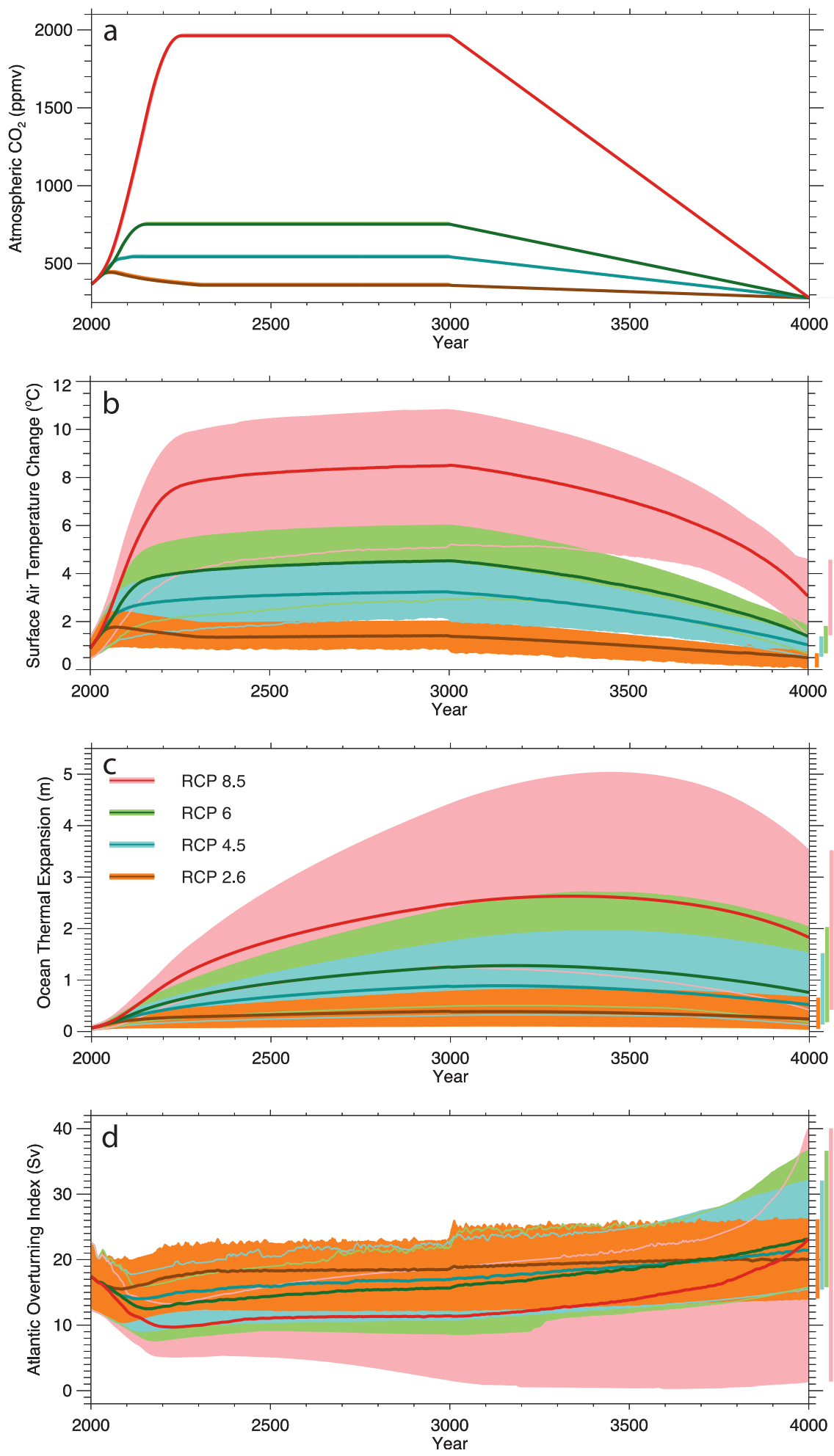

FIG. 12. As in Fig. 11, but for REb simulations with atmospheric $\mathrm{CO}_{2}$ after year 3000 decreasing to preindustrial levels over $1000 \mathrm{yr}$. 

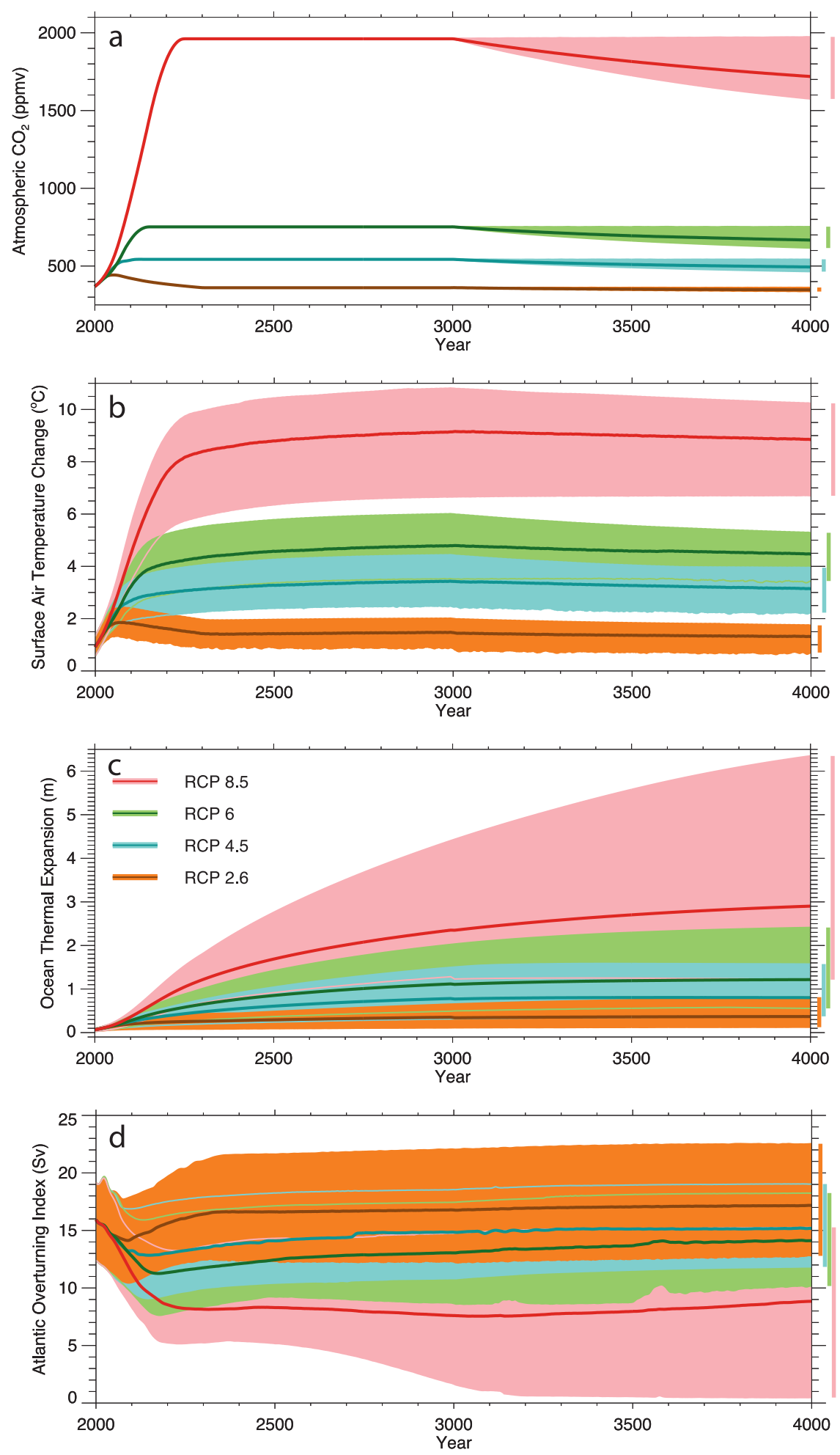

FIG. 13. As in Fig. 11, but for REc simulations with atmospheric $\mathrm{CO}_{2}$ after year 3000 evolving freely (zero emissions). These experiments were performed by EMICs with an interactive carbon cycle only. 

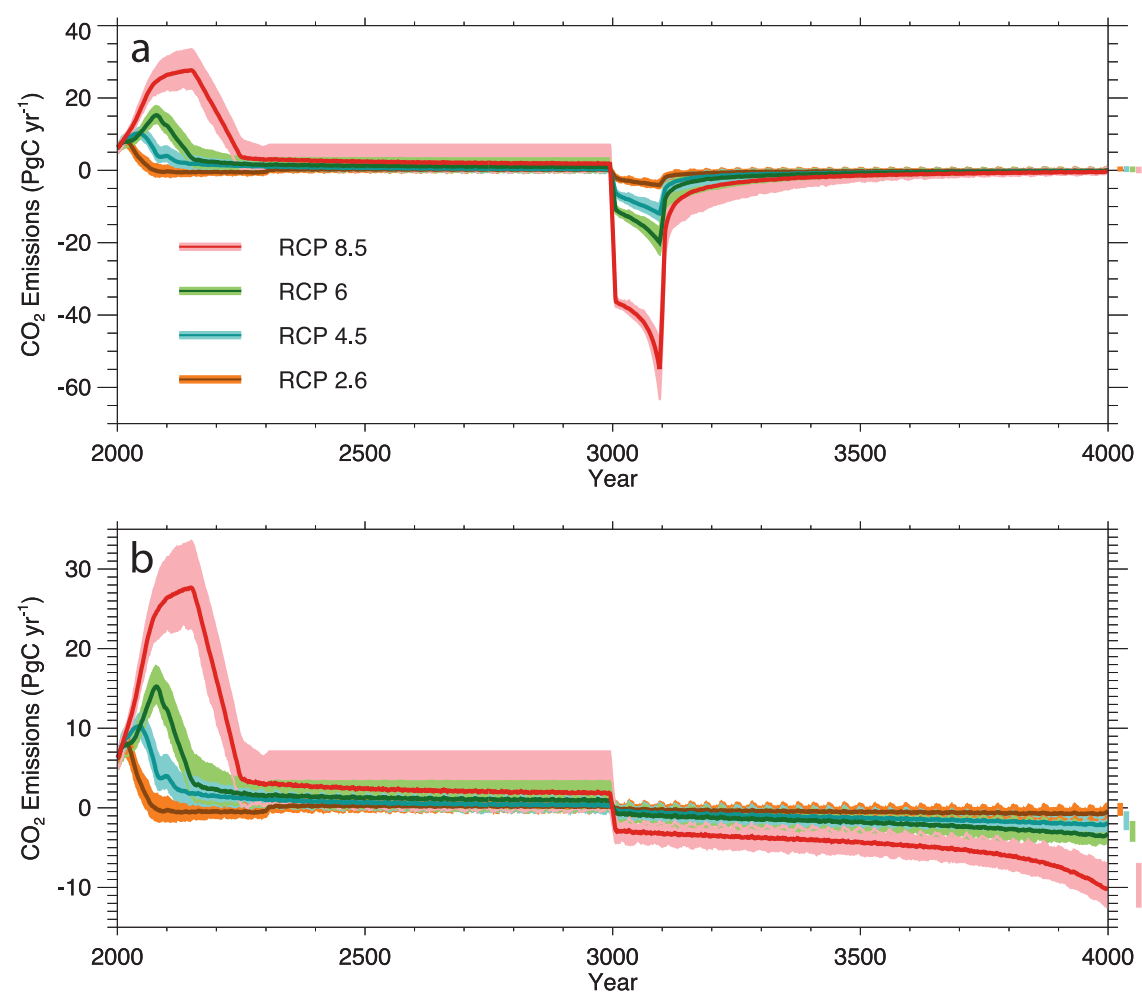

FIG. 14. Diagnosed $\mathrm{CO}_{2}$ emissions for reversibility simulations with atmospheric $\mathrm{CO}_{2}$ after year 3000 decreasing to preindustrial levels over (a) 100 and (b) $1000 \mathrm{yr}$. Results are shown for seven EMICs with an interactive carbon cycle. Shown are the model ensemble averages (thick solid lines), the ranges spanned by all models (shaded domains, delimited by thin solid lines), and the range in the year 3000 (vertical bars on right- side). Note the different vertical scales in (a) and (b).

a high total carbon uptake sensitivity to temperature, but also a high total carbon uptake sensitivity to $\mathrm{CO}_{2}$ (see Tables 2 and 4 of Eby et al. 2013). The relative ordering of these sensitivities between the two models is time and scenario dependent (e.g., the equilibrium climate sensitivity is higher in UVic than Bern3D-LPJ at $2 \times \mathrm{CO}_{2}$, but lower at $4 \times \mathrm{CO}_{2}$ ), which may explain the change in ordering of allowable emissions with the level of temperature stabilization.

Matthews et al. (2009) proposed the climate-carbon response (CCR), defined as the ratio of temperature change to cumulative carbon emissions, as a metric for the combined physical and biogeochemical response of the climate system to $\mathrm{CO}_{2}$ emissions. $\mathrm{CCR}$ has been suggested to be relatively insensitive to the emissions scenario and approximately constant over time. Eby et al. (2013) calculated the CCR for eight EMICs with an interactive carbon cycle from an idealized $4 \times \mathrm{CO}_{2}$ experiment with a $1 \% \mathrm{CO}_{2}$ increase per year and noted that the CCR in the EMICs varies appreciably with time. At the time of $\mathrm{CO}_{2}$ doubling, the CCR ranges from 1.4 to $2.5^{\circ} \mathrm{C} \mathrm{EgC}^{-1}$ [note that these numbers differ from those in Table 4 of
Eby et al. (2013), which are taken at the time of $\mathrm{CO}_{2}$ quadrupling]. The models' CCR can be inverted to compute the range of cumulative emissions consistent with temperature targets. Ensemble mean allowable cumulative emissions are $830,1100,1650$, and $2200 \mathrm{PgC}$ for temperature targets of $1.5^{\circ}, 2^{\circ}, 3^{\circ}$, and $4^{\circ} \mathrm{C}$, respectively (Fig. 17). Since the CCR was computed for cumulative emissions of about $1000 \mathrm{PgC}$, CCR-based allowable emission estimates for temperature targets of $1.5^{\circ}-2^{\circ} \mathrm{C}$ are likely more accurate than those for the higher temperature targets. While the cumulative emissions estimated from the temperature tracking experiments and the CCR are very similar for the Bern3D-LPJ model, particularly for lower temperature targets, the CCRderived estimates are considerably higher for the UVic model. The difference in the UVic model's allowable emissions estimates for the low temperature targets could be explained by a net positive radiative forcing from non$\mathrm{CO}_{2}$ sources in the temperature tracking simulations (not present in the idealized $4 \times \mathrm{CO}_{2}$ simulation from which the CCR was derived), which reduces the amount of allowable $\mathrm{CO}_{2}$ emissions. Because of differences in forcing 

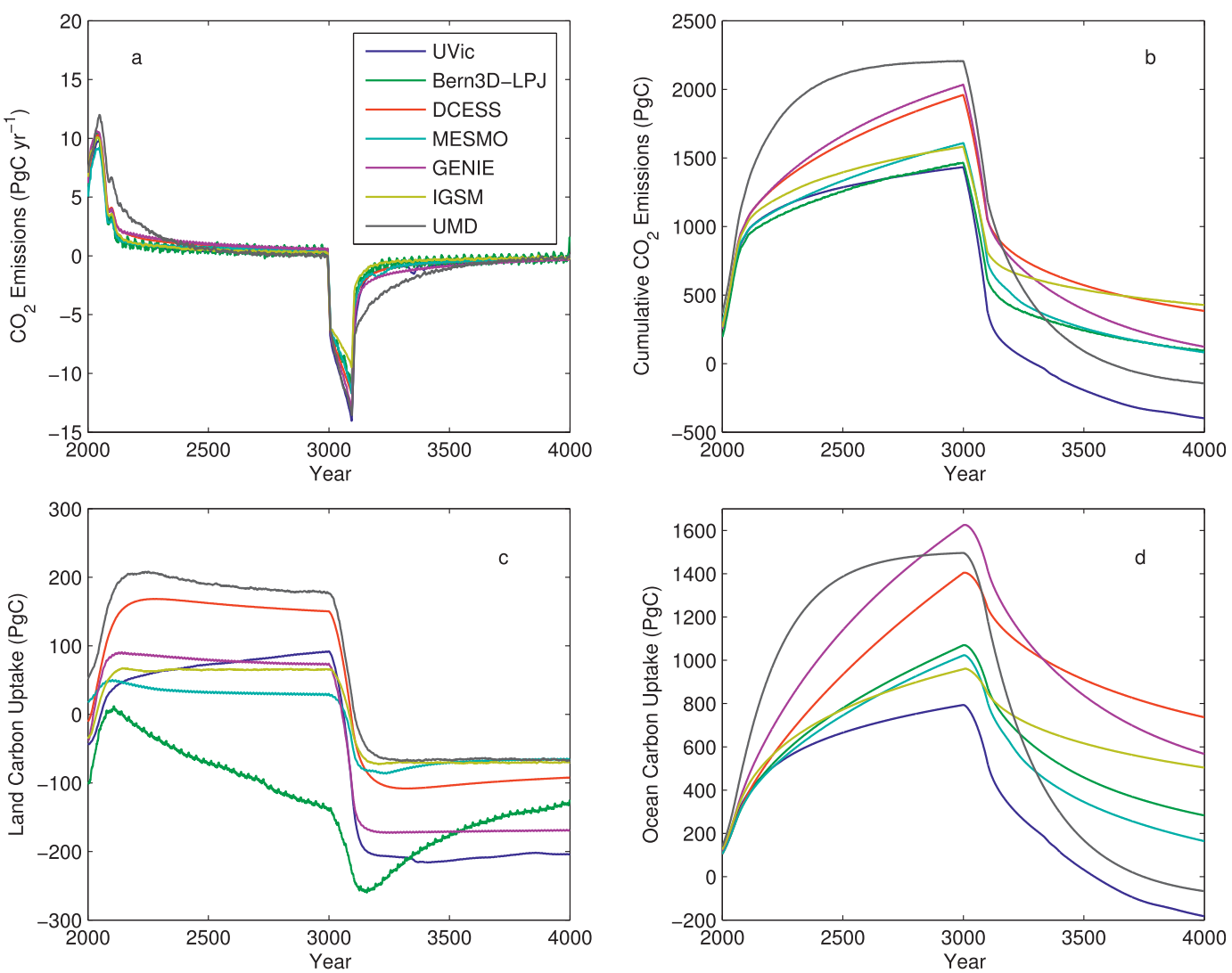

FIG. 15. Changes in carbon inventories for the RCP4.5 REa simulation with atmospheric $\mathrm{CO}_{2}$ after year 3000 decreasing to preindustrial levels over $100 \mathrm{yr}$ (a) $\mathrm{CO}_{2}$ emissions, (b) cumulative $\mathrm{CO}_{2}$ emissions since 1850, (c) land uptake since 1850, and (d) ocean uptake since 1850. Data in (a) were smoothed using a 10-yr moving average.

implementation, the non- $\mathrm{CO}_{2}$ radiative forcing imbalance seems not to be present in the Bern3D-LPJ temperature tracking runs, such that the two allowable emissions estimates are very similar for low temperature targets. For higher targets, the discrepancy between the CCR-based and temperature-tracking-derived estimates is likely a result of the time and scenario dependence of CCR.

\section{Summary and conclusions}

We presented results from long-term climate projections with 12 EMICs. The first set of projections contains climate change commitment simulations to the year 3000. Three different types of climate commitment are considered: 1) constant composition, 2) preindustrial emission, and 3) constant emission commitments. All commitment simulations follow common $\mathrm{CO}_{2}$ concentration trajectories until the year 2300: the four RCP scenarios $(2.6,4.5,6.0$, and 8.5) and their extensions. Climate projections to 2300 are consistent with results from AOGCMs, confirming that EMICs are well suited to complement simulations with more complex models. Simulated ensemble-mean surface air temperatures exceed the $2^{\circ} \mathrm{C}$ target set by the Copenhagen Accord in all scenarios, except for the low-emissions RCP2.6 scenario. Under this scenario, the model ensemble mean temperature peaks at $1.7^{\circ} \mathrm{C}$ relative to preindustrial, and returns to $1.3^{\circ} \mathrm{C}$ by 2300 . The spread between models, however, is considerable, and peak warming in a few models exceeds the $2^{\circ} \mathrm{C}$ target.

EMICs simulate substantial surface air temperature and thermosteric sea level rise commitment following stabilization of the atmospheric composition at year-2300 levels for RCPs 4.5, 6.0, and 8.5. For these scenarios, the thermosteric sea level rise between years 2300 and 3000 amounts to several times the sea level rise by the time of radiative forcing stabilization. Sea level rise due to thermal expansion still continues at the year 3000 under all scenarios considered. The Atlantic meridional overturning circulation is weakened temporarily under RCPs 2.6-6.0 and recovers to within $80 \%$ of the preindustrial value several centuries after forcing stabilization. The MOC weakening is more persistent for RCP8.5, with one model close to a complete collapse in the year 3000 .

EMICs with an interactive carbon cycle are used to diagnose the $\mathrm{CO}_{2}$ emissions compatible with the $\mathrm{CO}_{2}$ 

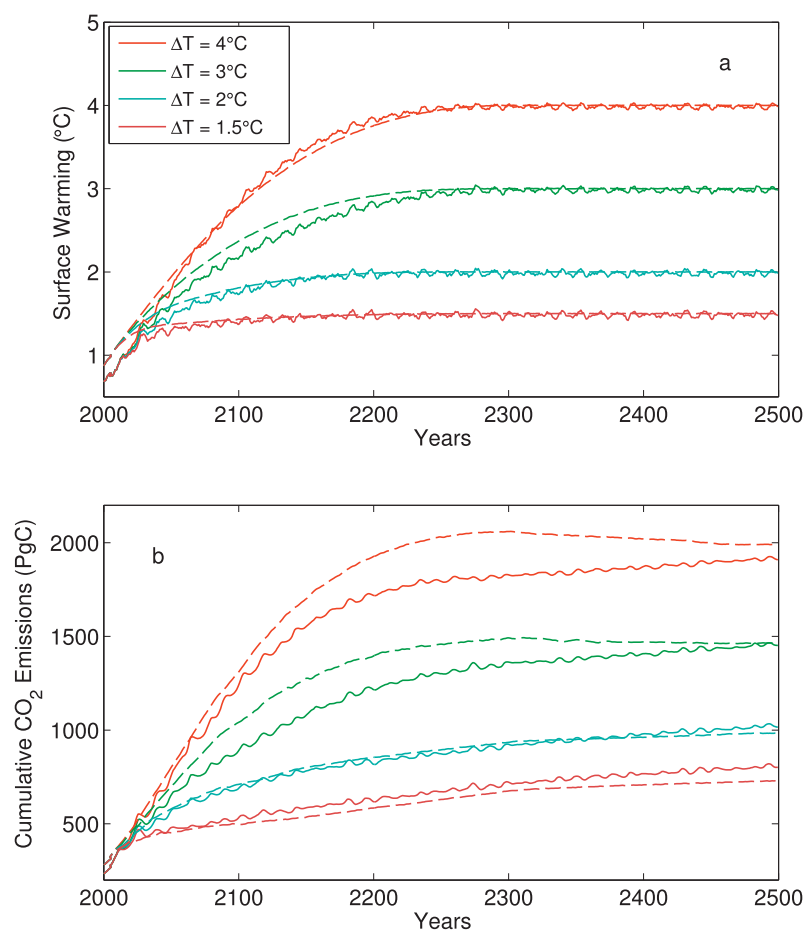

FIG. 16. Cumulative $\mathrm{CO}_{2}$ emissions compatible with a set of longterm temperature targets $\left(1.5^{\circ}-4^{\circ} \mathrm{C}\right)$ for temperature tracking experiments with two EMICs: UVic (dashed) and Bern3D-LPJ (solid). (a) Surface air temperature change relative to preindustrial (1800 for UVic and 850 for Bern3D-LPJ). (b) Cumulative $\mathrm{CO}_{2}$ emissions since preindustrial.

concentration pathways specified for the constant composition commitment simulations. Diagnosed cumulative emissions between 1850 and 3000 increase approximately linearly with atmospheric $\mathrm{CO}_{2}$ for RCPs $2.6-6.0$, but the increase becomes less than linear at higher radiative forcing. The year-3000 airborne fraction of cumulative emissions increases with increasing atmospheric $\mathrm{CO}_{2}$. The increasing airborne fraction is due largely to a decrease in the ocean uptake fraction with higher radiative forcing. The model ensemble mean land uptake fraction is rather constant across RCP scenarios, but the $\mathrm{CO}_{2}$ dependence varies strongly between models.

Elimination of anthropogenic $\mathrm{CO}_{2}$ emissions after 2300 and constant year-2300 non- $\mathrm{CO}_{2}$ radiative forcing result in slowly decreasing atmospheric $\mathrm{CO}_{2}$ concentrations. At year 3000 atmospheric $\mathrm{CO}_{2}$ is still at more than half the year-2300 level in all EMICs for RCPs 4.5-8.5, with the fraction increasing with RCP scenario. Surface air temperature remains nearly constant or decreases slightly in all EMICs, with $85 \%-99 \%$ of the maximum warming still persisting in the year 3000 for RCPs 4.5-8.5. Sea level rise due to thermal expansion continues after elimination of $\mathrm{CO}_{2}$ emissions in RCPs 4.5-8.5 and is comparable to the sea level rise between 1850 and 2300. At 3000, 700 years

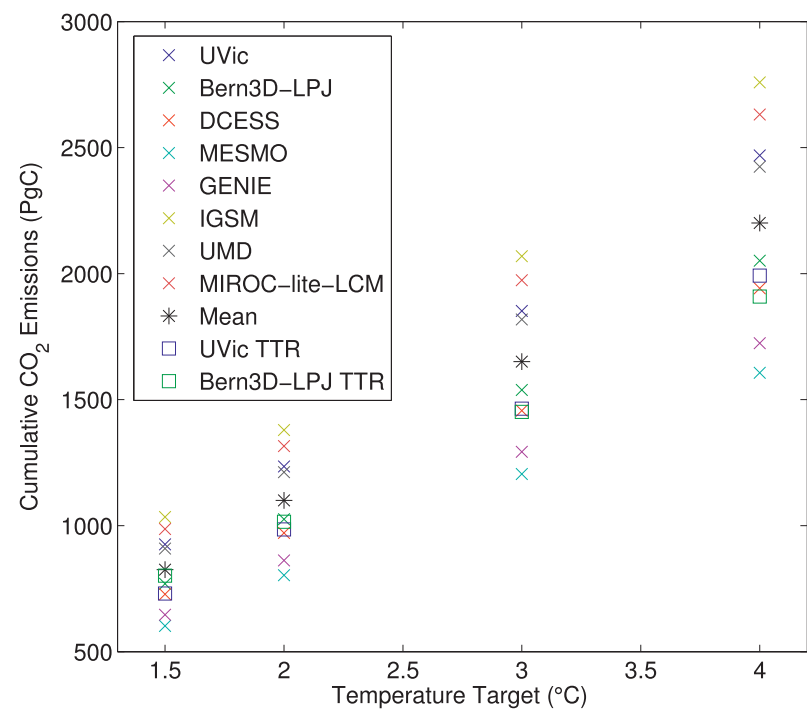

FIG. 17. Cumulative $\mathrm{CO}_{2}$ emissions compatible with a set of longterm temperature targets $\left(1.5^{\circ}-4^{\circ} \mathrm{C}\right)$ for EMICs with an interactive carbon cycle. Allowable cumulative emissions are derived from the models' CCR). Also shown are the year-2500 cumulative emissions derived from TTR experiments with the UVic and Bern3D-LPJ EMICs (square symbols).

after anthropogenic $\mathrm{CO}_{2}$ emissions are zeroed, sea level is still rising in several EMICs. If radiative forcing from non$\mathrm{CO}_{2}$ forcing agents is eliminated simultaneously with $\mathrm{CO}_{2}$ emissions, temperature and thermosteric sea level decline slightly faster than in the simulations with elimination of $\mathrm{CO}_{2}$ emissions alone, but still remain substantially higher in the year 3000 compared to preindustrial.

The largest warming and thermosteric sea level rise commitment are simulated for the case with $\mathrm{CO}_{2}$ emissions held fixed at year-2300 levels and constant year2300 non- $\mathrm{CO}_{2}$ radiative forcing. In response to increasing atmospheric $\mathrm{CO}_{2}$ levels after 2300, surface air temperature and sea level continue to rise, with a substantial post2300 commitment.

The climate change commitment associated with the low emissions scenario RCP2.6 differs from that of the higher RCPs. Because of the decline in atmospheric $\mathrm{CO}_{2}$ and radiative forcing already before 2300 , the warming and thermosteric sea level rise commitment after 2300 are lower in this scenario. The difference is largest for the constant emissions commitment simulations, since year-2300 emissions are negative (as opposed to positive in the other scenarios). Accordingly, atmospheric $\mathrm{CO}_{2}$ decreases after 2300, surface air temperature continues to cool, and sea level starts to fall.

Results of the climate change commitment simulations differ widely between EMICs, both in the physical and biogeochemical response. The difference in the response 
of the terrestrial carbon cycle to atmospheric $\mathrm{CO}_{2}$ and climate is particularly large. Compared to an earlier EMIC intercomparison (Plattner et al. 2008), the range of carbon cycle responses appears to have even widened. This may be explained by the larger number of coupled climate-carbon cycle models included in the present model intercomparison and the increase in model complexity since the Plattner et al. (2008) study. Most EMICs now include interactive representation of land use change emissions. One model includes representation of carbon release from permafrost and peatlands, while another includes nitrogen limitation. On the ocean side, several models now include representation of sediment processes. The large model spread suggests that continued efforts are needed to better understand the processes driving the response of land and ocean uptake to $\mathrm{CO}_{2}$ and climate, and to better represent these processes in models.

If $\mathrm{CO}_{2}$ emissions cease, and it is left to the natural carbon sinks to take up excess $\mathrm{CO}_{2}$, atmospheric $\mathrm{CO}_{2}$ declines only slowly, and climate change is largely irreversible on centennial to millennial time scales, as discussed above in the context of the preindustrial emission commitment simulations. Two additional experiments were carried out by EMICs to explore the reversibility of the climate system in response to an artificial "ramp down" of atmospheric $\mathrm{CO}_{2}$ to preindustrial levels (over $100-1000 \mathrm{yr}$ ). Because of the large thermal inertia of the ocean, surface air temperature and thermosteric sea level exhibit a substantial time lag relative to atmospheric $\mathrm{CO}_{2}$. Even 900 years after $\mathrm{CO}_{2}$ is restored to preindustrial levels, surface air temperature and particularly sea level are still considerably higher than under 1851-60 conditions. The thermohaline circulation strengthens rapidly during the $\mathrm{CO}_{2}$ decrease phase, first overshooting and then slowly converging to the preindustrial value. If atmospheric $\mathrm{CO}_{2}$ is returned to preindustrial levels more slowly (over $1000 \mathrm{yr}$ ), surface air temperature also cools more slowly, and sea level continues to rise for several centuries before starting to fall. The model ensemble mean thermohaline circulation recovers slowly at first and more rapidly toward the end of the $\mathrm{CO}_{2}$ decrease phase. The ramp down of $\mathrm{CO}_{2}$ to preindustrial levels over 100-1000 yr requires large negative emissions (i.e., net removal of $\mathrm{CO}_{2}$ from the atmosphere), which are likely unrealistic with technologies currently available to capture $\mathrm{CO}_{2}$ from the atmosphere (McGlashan et al. 2012).

In summary, results from the commitment and reversibility simulations suggest that it is very difficult to revert from a given level of warming on time scales relevant to human activities, even after complete elimination of emissions. Reversing global warming may be desirable if climate change exceeds adaptive capacities of natural and human systems. Our results suggest that significant negative emissions have the potential to reverse global warming but whether $\mathrm{CO}_{2}$ capture technology is feasible at the necessary scale is debatable.

Using an inverse modeling approach, two EMICs (Bern3D-LPJ and UVic) estimated the cumulative $\mathrm{CO}_{2}$ emissions $\left(\mathrm{CO}_{2}\right.$ budget $)$ compatible with long-term global mean temperature stabilization targets. Cumulative emissions between preindustrial and the year 2500 are similar between the two models and amount to a mean value of $1000 \mathrm{PgC}$ for $2^{\circ} \mathrm{C}$. A somewhat higher model ensemble mean estimate is derived based on the climate-carbon response (CCR; Matthews et al. 2009) computed for EMICs with an interactive carbon cycle. As cumulative $\mathrm{CO}_{2}$ emissions from fossil fuels and land use up to today amount to about $500 \mathrm{PgC}$, the remaining $\mathrm{CO}_{2}$ budget consistent with the $2^{\circ} \mathrm{C}$ target is about $500 \mathrm{PgC}$, assuming that the radiative forcing of non- $\mathrm{CO}_{2}$ greenhouse gases continues to be compensated by negative aerosol forcing, as has been approximately the case in the past. The results of this model intercomparison therefore support the conclusions from previous studies that it is still possible in theory to meet the $2^{\circ} \mathrm{C}$ target, but leeway is getting tight, particularly in the face of socioeconomic and technological inertia.

Acknowledgments. $\mathrm{KZ}$ and AJW acknowledge support from the National Science and Engineering Research Council (NSERC) Discovery Grant Program. AJW acknowledges support from NSERC's G8 Research Councils Initiative on Multilateral Research Funding Program. AVE and IIM were supported by the President of Russia Grant 5467.2012.5, by the Russian Foundation for Basic Research, and by the programs of the Russian Academy of Sciences. EC, TF, HG, and GPB acknowledge support from the Belgian Federal Science Policy Office. FJ, RS, and MS acknowledge support by the Swiss National Science Foundation and by the European Project CARBOCHANGE (Grant 264879), which received funding from the European Commission's Seventh Framework Programme (FP7/2007-2013). PBH and NRE acknowledge support from EU FP7 Grant ERMITAGE 265170.

\section{REFERENCES}

Allen, M. R., D. J. Frame, C. Huntingford, C. D. Jones, J. A. Lowe, M. Meinshausen, and N. Meinshausen, 2009: Warming caused by cumulative carbon emissions towards the trillionth tonne. Nature, 458, 1163-1166.

Archer, D., and V. Brovkin, 2008: The millennial atmospheric lifetime of anthropogenic $\mathrm{CO}_{2}$. Climatic Change, 90, 283-297, doi:10.1007/s10584-008-9413-1.

, and Coauthors, 2009: Atmospheric lifetime of fossil fuel carbon dioxide. Annu. Rev. Earth Planet. Sci., 37, 117-134, doi:10.1146/annurev.earth.031208.100206. 
Armour, K. C., and G. H. Roe, 2011: Climate commitment in an uncertain world. Geophys. Res. Lett., 38, L01707, doi:10.1029/ 2010 GL045850.

Arora, V. K., and Coauthors, 2011: Carbon emission limits required to satisfy future representative concentration pathways of greenhouse gases. Geophys. Res. Lett., 38, L05805, doi:10.1029/2010GL046270.

Azar, C., K. Lindgren, E. Larson, and K. Möllersten, 2006: Carbon capture and storage from fossil fuels and biomass costs and potential role in stabilizing the atmosphere. Climatic Change, 47, 47-79.

Boucher, O., and Coauthors, 2012: Reversibility in an Earth system model in response to $\mathrm{CO}_{2}$ concentration changes. Environ. Res. Lett., 7, 024013, doi:10.1088/1748-9326/7/2/024013.

Denman, K. L., and Coauthors, 2007: Coupling between changes in the climate system and biogeochemistry. Climate Change 2007: The Physical Science Basis, S. Solomon et al., Eds., Cambridge University Press, 499-587.

Eby, M., K. Zickfeld, A. Montenegro, D. Archer, K. J. Meissner, and A. J. Weaver, 2009: Lifetime of anthropogenic climate change: Millennial time scales of potential $\mathrm{CO}_{2}$ and temperature perturbations. J. Climate, 22, 2501-2511.

— , and Coauthors, 2013: Historical and idealized climate model experiments: An EMIC intercomparison. Climate Past, 9, 1111-1140.

Eliseev, A. V., and I. I. Mokhov, 2011: Uncertainty of climate response to natural and anthropogenic forcings due to different land use scenarios. Adv. Atmos. Sci., 28, 1215-1232, doi:10.1007/ s00376-010-0054-8.

Friedlingstein, P., and Coauthors, 2006: Climate-carbon cycle feedback analysis: Results from the C4MIP model intercomparison. J. Climate, 19, 3337-3353.

Frölicher, T., and F. Joos, 2010: Reversible and irreversible impacts of greenhouse gas emissions in multi-century projections with a comprehensive climate-carbon model. Climate Dyn., 35, 1439-1459, doi:10.1007/s00382-009-0727-0.

Gillett, N., V. Arora, K. Zickfeld, S. Marshall, and W. Merryfield, 2011: Ongoing climate change following a complete cessation of carbon dioxide emissions. Nat. Geosci., 4, 83-87.

Goosse, H., and Coauthors, 2010: Description of the earth system model of intermediate complexity LOVECLIM version 1.2. Geosci. Model Dev., 3, 603-633, doi:10.5194/ gmd-3-603-2010.

Hansen, J., G. Russell, A. Lacis, I. Fung, D. Rind, and P. Stone, 1985: Climate response times: Dependence on climate sensitivity and ocean mixing. Science, 229, 857-859, doi:10.1126/ science.229.4716.857.

Hare, B., and M. Meinshausen, 2006: How much warming are we committed to and how much can be avoided? Climatic Change, 75, 111-149, doi:10.1007/s10584-005-9027-9.

Held, I. M., M. Winton, K. Takahashi, T. Delworth, F. Zeng, and G. K. Vallis, 2010: Probing the fast and slow components of global warming by returning abruptly to preindustrial forcing. J. Climate, 23, 2418-2427.

Holden, P. B., N. R. Edwards, D. Gerten, and S. Schaphoff, 2013: A model based constraint on $\mathrm{CO}_{2}$ fertilisation. Biogeosciences, 10, 339-355, doi:10.5194/bg-10-339-2013.

Johansson, T. B., A. P. Patwardhan, N. Nakićenović, and L. GomezEcheverri, Eds., 2012: Global Energy Assessment: Toward a Sustainable Future. Cambridge University Press, 1882 pp.

Keith, D., M. Ha-Duong, and J. Stolaroff, 2006: Climate strategy with $\mathrm{CO}_{2}$ capture from the air. Climatic Change, 74, 17-45, doi:10.1007/s10584-005-9026-x.
Knutti, R., and J. Sedláček, 2013: Robustness and uncertainties in the new CMIP5 climate model projections. Nat. Climate Change, 3, 369-373, doi:10.1038/NCLIMATE1716.

Levitus, S., and Coauthors, 2012: World ocean heat content and thermosteric sea level change $(0-2000 \mathrm{~m}), 1955-2010$. Geophys. Res. Lett., 39, L10603, doi:10.1029/2012GL051106.

Lowe, J. A., C. Huntingford, S. C. B. Raper, C. D. Jones, S. K. Liddicoat, and L. K. Gohar, 2009: How difficult is it to recover from dangerous levels of global warming? Environ. Res. Lett., 4, 014012, doi:10.1088/1748-9326/4/1/014012.

MacDougall, A., C. Avis, and A. Weaver, 2012: Significant existing commitment to warming from the permafrost carbon feedback. Nat. Geosci., 5, 719-721.

Matsumoto, K., K. S. Tokos, A. R. Price, and S. J. Cox, 2008: First description of the Minnesota Earth System Model for Ocean biogeochemistry (MESMO 1.0). Geosci. Model Dev., 1, 1-15.

Matthews, H. D., and K. Caldeira, 2008: Stabilizing climate requires near-zero emissions. Geophys. Res. Lett., 35, L04705, doi:10.1029/2007GL032388.

_ and A. J. Weaver, 2010: Committed climate warming. Nat. Geosci., 3, 142-143, doi:10.1038/ngeo813.

_ , and K. Zickfeld, 2012: Climate response to zeroed emissions of greenhouse gases and aerosols. Nat. Climate Change, 2, 338-341, doi:10.1038/nclimate1424.

— N. P. Gillett, P. A. Stott, and K. Zickfeld, 2009: The proportionality of global warming to cumulative carbon emissions. Nature, 459, 829-832.

McGlashan, N., N. Shah, B. Caldecott, and M. Workman, 2012: High-level techno-economic assessment of negative emissions technologies. Process Saf. Environ. Prot., 90, 501-510.

Meehl, G., W. Washington, W. Collins, J. Arblaster, A. Hu, L. Buja, W. Strand, and H. Teng, 2005: How much more global warming and sea level rise? Science, 307, 1769-1772, doi:10.1126/ science. 1106663 .

— , and Coauthors, 2007: Global climate projections. Climate Change 2007: The Physical Science Basis, S. Solomon et al., Eds., Cambridge University Press, 747-845.

Meinshausen, M., N. Meinshausen, W. Hare, S. C. B. Raper, K. Frieler, R. Knutti, D. Frame, and M. Allen, 2009: Greenhouse-gas emission targets for limiting global warming to $2^{\circ} \mathrm{C}$. Nature, 458, 1158-1162.

_ , and Coauthors, 2011: The RCP greenhouse gas concentrations and their extensions from 1765 to 2300 . Climatic Change, 109, 213-241, doi:10.1007/s10584-011-0156-Z.

Montenegro, A., V. Brovkin, M. Eby, D. E. Archer, and A. J. Weaver, 2007: Long term fate of anthropogenic carbon. Geophys. Res. Lett., 34, L19707, doi:10.1029/2007GL030905.

Montoya, M., A. Griesel, A. Levermann, J. Mignot, M. Hofmann, A. Ganopolski, and S. Rahmstorf, 2005: The earth system model of intermediate complexity CLIMBER-3 $\alpha$. Part I: Description and performance for present-day conditions. Climate Dyn., $\mathbf{2 5}$, 237-263, doi:10.1007/s00382-005-0044-1.

Morice, C. P., J. J. Kennedy, N. A. Rayner, and P. D. Jones, 2013: Quantifying uncertainties in global and regional temperature change using an ensemble of observational estimates: The HadCRUT4 dataset. J. Geophys. Res., 117, D08101, doi:10.1029/ 2011JD017187.

Moss, R. H., and Coauthors, 2010: The next generation of scenarios for climate change research and assessment. Nature, 463, 747756, doi: $10.1038 /$ nature 08823 .

Nusbaumer, J., and K. Matsumoto, 2008: Climate and carbon cycle changes under the overshoot scenario. Global Planet. Change, 62, 164-172. 
Petoukhov, V., A. Ganopolski, V. Brovkin, M. Claussen, A. Eliseev, C. Kubatzki, and S. Rahmstorf, 2000: CLIMBER-2: A climate system model of intermediate complexity. Part I: Model description and performance for present climate. Climate Dyn., 16, 1-17, doi:10.1007/PL00007919.

Plattner, G.-K., and Coauthors, 2008: Long-term climate commitments projected with climate-carbon cycle models. J. Climate, 21, 2721-2751.

Purkey, S. G., and G. C. Johnson, 2010: Warming of global abyssal and deep southern ocean waters between the 1990s and 2000s: Contributions to global heat and sea level rise budgets. J. Climate, 23, 6336-6351.

Ritz, S. P., T. F. Stocker, and F. Joos, 2011: A coupled dynamical ocean-energy balance atmosphere model for paleoclimate studies. J. Climate, 24, 349-375.

Sabine, C. L., and Coauthors, 2004: The oceanic sink for anthropogenic $\mathrm{CO}_{2}$. Science, 305, 367-371.

Shaffer, G., S. M. Olsen, and J. O. P. Pedersen, 2008: Presentation, calibration and validation of the low-order, DCESS Earth system model (version 1). Geosci. Model Dev., 1, 17-51.

Sokolov, A., and Coauthors, 2005: The MIT Integrated Global System Model (IGSM) version 2: Model description and baseline evaluation. MIT Tech. Rep. 124, 40 pp.

Solomon, S., G.-K. Plattner, R. Knutti, and P. Friedlingstein, 2009: Irreversible climate change due to carbon dioxide emissions. Proc. Natl. Acad. Sci. USA, 106, 1704-1709.

_ J. J. Daniel, T. J. Sanford, D. M. Murphy, G.-K. Plattner, R. Knutti, and P. Friedlingstein, 2010: Persistence of climate changes due to a range of greenhouse gases. Proc. Natl. Acad. Sci. USA, 107, 18354-18359, doi:10.1073/pnas.1006282107.

Stocker, B. D., K. Strassmann, and F. Joos, 2011: Sensitivity of Holocene atmospheric $\mathrm{CO}_{2}$ and the modern carbon budget to early human land use: Analyses with a process-based model. Biogeosciences, 8, 69-88.
Tachiiri, K., J. C. Hargreaves, J. D. Annan, A. Oka, A. Abe-Ouchi, and M. Kawamiya, 2010: Development of a system emulating the global carbon cycle in Earth system models. Geosci. Model Dev., 3, 365-376, doi:10.5194/gmd-3-365-2010.

Taylor, K. E., R. J. Stouffer, and G. A. Meehl, 2012: An overview of CMIP5 and the experiment design. Bull. Amer. Meteor. Soc., 93, 485-498.

Tsutsui, J., Y. Yoshida, D.-H. Kim, H. Kibata, K. Nishizawa, N. Nakashiki, and K. Murayama, 2007: Long-term climate response to stabilized and overshoot anthropogenic forcings beyond the twenty-first century. Climate Dyn., 28, 199-214.

Weaver, A. J., and Coauthors, 2001: The UVic Earth system climate model: Model description, climatology, and applications to past, present, and future climates. Atmos.-Ocean, 39, 361428.

Wigley, T., 2005: The climate change commitment. Science, 307, 1766-1769, doi:10.1126/science.1103934.

Yin, J., 2012: Century to multi-century sea level rise projections from CMIP5 models. Geophys. Res. Lett., 39, L17709, doi:10.1029/2012GL052947.

Yoshida, Y., K. Maruyama, J. Tsutsui, N. Nakashiki, F. O. Bryan, M. Blackmon, B. A. Boville, and R. D. Smith, 2005: Multi-century ensemble global warming projections using the Community Climate System Model (CCSM3). J. Earth Simul., 3, 2-10.

Zeng, N., H. Qian, E. Munoz, and R. Iacono, 2004: How strong is carbon cycle-climate feedback under global warming? Geophys. Res. Lett., 31, L20203, doi:10.1029/2004GL020904.

Zickfeld, K., M. Eby, H. Matthews, and A. J. Weaver, 2009: Setting cumulative emissions targets to reduce the risk of dangerous climate change. Proc. Natl. Acad. Sci. USA, 106 (38), 16129 16134.

, V. K. Arora, and N. P. Gillett, 2012: Is the climate response to $\mathrm{CO}_{2}$ emissions path dependent? Geophys. Res. Lett., 39, L05703, doi:10.1029/2011GL050205. 